\title{
Litoquímica e química mineral da Formação Quarenta Ilhas no Distrito Mineiro de Pitinga (AM)
}

\author{
Ronaldo Pierosan ${ }^{1}$, Evandro Fernandes de Lima ${ }^{2}$, Cristina P. de Campos ${ }^{3}$, Artur Cezar Bastos \\ Neto $^{2}$, Lauro Valentin Stoll Nardi', José Maximino Tadeu Miras Ferron ${ }^{4}$ \& Mauricio Prado ${ }^{4}$
}

\begin{abstract}
Resumo A Formação Quarenta Ilhas consiste de rochas subvulcânicas básicas a intermediárias, de afinidade toleítica e idade em torno de 1,78Ga. A mineralogia magmática é constituída por olivina, substituída pseudomorficamente por ferro-saponita, plagioclásio variando de labradorita a oligoclásio $\left(\mathrm{An}_{65} \mathrm{Ab}_{35}\right.$ a $\left.\mathrm{An}_{20} \mathrm{Ab}_{80}\right)$, óxidos de Fe-Ti $\left(\mathrm{Ilm}_{87-95}\right.$ e Usp $\left.{ }_{22-37}\right)$, diopsídio a augita $\left(\mathrm{Wo}_{44-35} \mathrm{En}_{44-21} \mathrm{Fs}_{38-16}\right)$, com ferro-hornblenda (textura coronítica), feldspato alcalino e quartzo nos termos mais diferenciados. Dados petrográficos e litoquímicos apontam para uma evolução por cristalização fracionada de diabásio/gabro até quartzo dioritos, compatível com fracionamento de olivina+ilmenita, magnetita+plagioclásio+augita, e cristalização de ferro-hornblenda, feldspato alcalino e quartzo em estágios tardios. A afinidade com magmas subalcalinos toleíticos é indicada pelos padrões de elementos maiores, proporções de minerais normativos (olivina+hiperstênio e quartzo+hiperstênio) e pelas elevadas razões $\mathrm{Y} / \mathrm{Nb}$ e $\mathrm{La} / \mathrm{Yb}$. Os elevados conteúdos de $\mathrm{Cs}, \mathrm{Rb}, \mathrm{Ba}$ e $\mathrm{K}$, e baixos de $\mathrm{Nb}$, Ta e Zr indicam participação de manto litosférico enriquecido em LILE e previamente modificado por subducção. O padrão de ETR é marcado por enriquecimento de ETRL em relação aos ETRP, o que sugere uma fonte com composição compatível com um granada lherzolito. O posicionamento dos corpos subvulcânicos da Formação Quarenta Ilhas, num ambiente francamente intracratônico, foi precedido pelas atividades orogenéticas relacionadas ao Ciclo Transamazônico ( 2,0Ga), pelo magmatismo pós-colisional Uatumã ( 1,88Ga) e pelo magmatismo anorogênico da Suíte Madeira $(\sim 1,83 \mathrm{Ga})$, num ambiente francamente intracratônico.
\end{abstract}

Palavras-chave: Craton Amazônico, Pitinga, geoquímica, química mineral, magmatismo toleítico.

\begin{abstract}
Lithochemistry and mineral chemistry of Quarenta Ilhas Formation in the Pitinga Mining District, Pitinga (AM), Brazil. The Quarenta Ilhas Formation consists of basic to intermediate subvolcanic rocks, with tholeitic affinity and ages around $1.78 \mathrm{Ga}$. The magmatic mineralogy is composed by olivine, pseudomorfosed by ferrous-saponite, plagioclase varying from labradorita to oligoclase $\left(\mathrm{An}_{65} \mathrm{Ab}_{35} \mathrm{a} \mathrm{An}_{20} \mathrm{Ab}_{80}\right)$, Fe-Ti oxides ( $\mathrm{Ilm}_{87-95}$ and $\left.\mathrm{Usp}_{22-37}\right)$, diopside to augite $\left(\mathrm{Wo}_{44-35} \mathrm{En}_{44-21} \mathrm{Fs}_{38-16}\right)$, with ferro-hornblende (as coronitic texture), alkali-feldspar and quartz in the most differentiated rocks. Petrographic and geochemical data point to an evolution through fractional crystallization from diabase/gabbro to quartz diorite, with fractionation of olivine+ilmenita, magnetite+plagioclase+augite, and crystallization of ferro-hornblende, alkali-feldspar and quartz in the later stages. The affinity with tholeiitic subalkaline magma is indicated by features of major elements, normative minerals (olivine+hypersthene and quartz+hypersthene) and high $\mathrm{Y} / \mathrm{Nb}$ and $\mathrm{La} / \mathrm{Yb}$ ratios. High $\mathrm{Cs}, \mathrm{Rb}, \mathrm{Ba}$ and $\mathrm{K}$, and low $\mathrm{Nb}$, Ta and $\mathrm{Zr}$, suggest a lithospheric mantle source, enriched in LILE and depleted by subduction. The REE pattern is LREE enriched faced to HREE, that suggest a source of garnet lherzolitic composition. The emplacement of the Quarenta Ilhas subvolcanic bodies follow the orogenetic activity of the Transamazonian Cycle $(\sim 2.0 \mathrm{Ga})$, the post-collisional Uatumã magmatismo $(\sim 1.88 \mathrm{Ga})$ and the anorogenic magmatism of the Madeira Suite $(\sim 1.83 \mathrm{Ga})$, in a fully intracratonic setting.
\end{abstract}

Keywords: Amazonian Craton, Pitinga, Geochemistry, Mineral Chemistry, tholeiitic magmatism.

INTRODUÇÃO A Formação Quarenta Ilhas (Veiga Jr. et al. 1979) é constituída por diabásios, gabros e dioritos de afinidade tolética e idade em torno de 1,78Ga. Os litotipos ocorrem sob a forma de corpos subvulcâ- nicos, intrusivos nas rochas sedimentares da Formação Urupi. Nesse contexto, são identificadas outras ocorrências no norte do Escudo das Guianas - evento Avanavero (Hebeda et al. 1973), e no Escudo Guaporé - evento

1 - UFRGS, Universidade Federal do Rio Grande do Sul, Programa de Pós-graduação em Geociências (PPGGeo), Instituto de Geociências, Porto Alegre (RS), Brasil. E-mail: ronaldo.pierosan@ufrgs.br

2 - UFRGS, Universidade Federal do Rio Grande do Sul, Centro de Pesquisas em Geoquímica (CPGq), Instituto de Geociências, Porto Alegre (RS), Brasil. E-mail: evandro.lima@ufrgs.br; artur.bastos@ufrgs.br; lauro.nardi@ufrgs.br

3 - Department für Geo- und Umweltwissenschaften - Ludwig-Maximilians-Universität München (LMU), München, Deutschland.

E-mail: campos@min.uni-muenchen.de

4 - Mineração Taboca S.A. - Grupo Paranapanema, Presidente Figueiredo-Vila Pitinga-AM-Brasil.

E-mail: jmaxferron@bol.com.br; mauricio_geo@yahoo.com.br 
Crepori (Pessoa et al. 1977, Bizinella et al. 1980, Santos \& Loguércio 1984). Santos et al. (2002) sugerem que o magmatismo que gerou os eventos Avanavero-Quarenta Ilhas-Crepori pode estar relacionado com os processos de fragmentação do Supercontinente Atlântica.

Na região do Distrito Mineiro de Pitinga, o conhecimento da Formação Quarenta Ilhas está vinculado a três trabalhos. O primeiro consiste de dados geoquímicos e geocronológicos provenientes do mapeamento geológico publicado por Veiga Jr. et al. (1979), quando da definição da unidade. O segundo está relacionado aos dados petrográficos publicados por Silva Jr. (inédito). O terceiro diz respeito à idade de $1780 \pm 3 \mathrm{Ma}$ atribuída por Santos et al. (2002) para um dique de diabásio. Dessa forma, a obtenção de dados geoquímicos (litoquímica e química mineral), disponibilizados neste trabalho, vêm a contribuir para o conhecimento geoló- gico do magmatismo Quarenta Ilhas.

CONTEXTO GEOLÓGICO A Formação Quarenta Ilhas se originou durante um período de estabilidade geotectônica no Escudo das Guianas. Os principais modelos geotectônicos do Cráton Amazônico (Tassinari \& Macambira 1999, Santos et al. 2000 e respectivas revisões) descrevem para a região, intensa atividade orogênica relacionada ao Ciclo Transamazônico entre 2,2Ga e 1,9Ga. A atividade orogênica foi seguida por um expressivo evento vulcano-plutônico em ambiente intraplaca (Magmatismo Uatumã, $1,88 \mathrm{Ga}$ ), e posterior estabilização geotectônica, caracterizada por sedimentação siliciclástica e magmatismo anorogênico a aproximadamente 1,83 Ga e 1,78 Ga.

Na região de Pitinga (Fig. 1), as unidades orogênicas consistem de gnaisses de fácies anfibolito a gra-
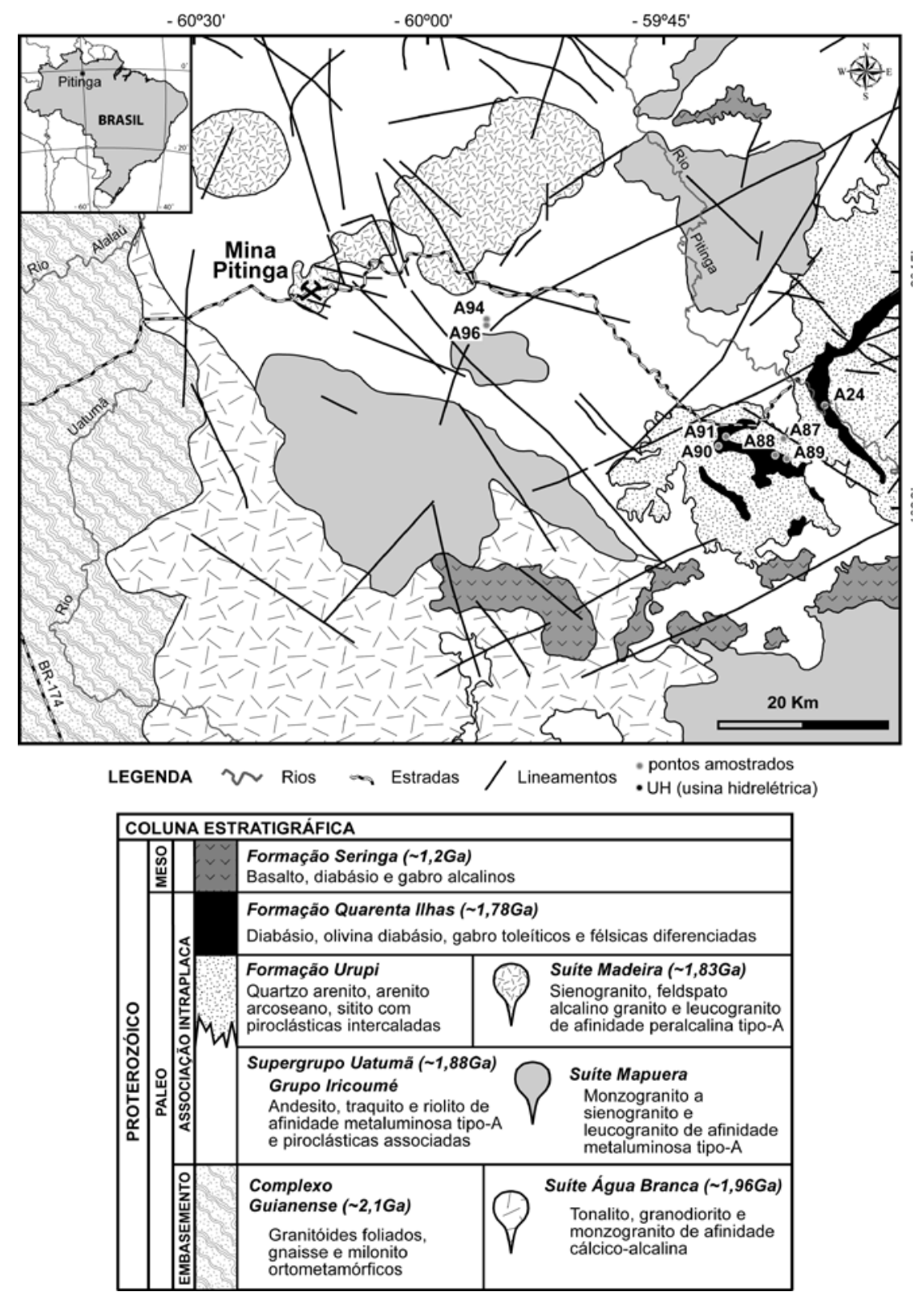

Figura 1 - Mapa Geológico de parte do Distrito Mineiro de Pitinga (modificado de Ferron et al. 2006). 
nulito, associados a migmatitos e granitóides de 2,0Ga, agrupados no Complexo Guianense (Issler et al. 1974, Araújo et al. 1976). A Suíte Intrusiva Água Branca é constituída por quartzo dioritos a granodioritos e monzogranitos, de afinidade cálcio-alcalina de médio a alto potássio, e idades entre 1,96Ga e 1,89Ga (Oliveira et al. 1996, Valério et al. 2006). O ambiente geotectônico de posicionamento da Suíte Intrusiva Água Branca é interpretado como sin- a pós-colisional (Valério et al. 2006).

O Magmatismo Uatumã, no Escudo das Guianas, é constituído pela associação vulcano-plutônica Iricoumé-Mapuera. As características geoquímicas indicam afinidade com magmas tipo-A, de caráter metaluminoso a fracamente peraluminoso (Ferron et al. 2010). O posicionamento dessa associação ocorreu entre $1,90 \mathrm{Ga}$ e $1,87 \mathrm{Ga}$ (Costi et al. 2000, Ferron et al. 2006), em regime extensional intraplaca, e ambiente pós-colisional (Ferron et al. 2010). A Suíte Intrusiva Mapuera é constituída por quartzo sienitos, e monzogranitos a feldspato-alcalino leucogranitos. As vulcânicas do Grupo Iricoumé consistem de andesitos a riolitos, associados a expressivos depósitos ignimbríticos, e tufos de queda, depósitos de surge e vulcanoclásticos subordinados (Ferron et al. 2006).

A deposição de pelitos, quartzo arenitos, arcoses e conglomerados da Formação Urupi (Veiga Jr. et al. 1979) ocorre nos estágios subsequentes ao vulcano-plutonismo Iricoumé-Mapuera. Tufos de queda e ignimbritos intercalados à sequência sedimentar estão possivelmente vinculados aos estágios finais do vulcanismo do Grupo Iricoumé (Ferron et al. 2006). A espessura da sequência sedimentar é estimada em mais de $800 \mathrm{~m}$ (Veiga Jr. et al. 1979), e marca a transição para um estágio francamente intracratônico na região. O posicionamento dos granitóides mineralizados ( $\mathrm{Sn}$, $\mathrm{Ta}, \mathrm{Nb}, \mathrm{Zr}, \mathrm{Y}, \mathrm{U}, \mathrm{F}$ e ETR) da Suíte Madeira (Costi et al. 2000) indica um estágio anorogênico para a região a cerca de 1,83Ga. Esses granitóides são constituídos por anfibólio-biotita sienogranito (rapakivi), biotita feldspato alcalino granito, albita granito e topázio granito, com assinaturas geoquímicas de magmas tipo-A com afinidade peralcalina (Horbe et al. 1991, Lenharo 1998, Costi et al. 2000, Lenharo et al. 2003).

A Formação Quarenta Ilhas ocorre na região de Pitinga sob forma de diques, soleira e stocks de diabásio, gabro, diorito e quartzo diorito. Esses corpos subvulcânicos intrudem rochas sedimentares da Formação Urupi através de estruturas regionais pré-existentes, e vulcânicas do Grupo Iricoumé. A estrutura mais expressiva da região é denominada de Braquissinclinal de Pitinga, caracterizada como uma feição topográfica elíptica com 20x60 km de extensão, onde os corpos intrusivos da Formação Quarenta Ilhas sustentam o relevo. Originalmente foi interpretada como uma estrutura tectônica formada pelo dobramento regional da sequência sedimentar (Mandetta et al. 1974, Veiga Jr. et. al. 1979). Montalvão (1975), Araujo et al. (1976) e Dall'Agnol et al. (1999), sugerem uma origem relacionada a processos de colapso de caldeira, geneticamente vinculados ao magmatismo Iricoumé-Mapuera.
No entanto, uma relação da estrutura com os litotipos vulcânicos não pode ser diretamente estabelecida. Estudos referentes às rochas vulcânicas da região de Pitinga (Ferron et al. 2006, 2010, Pierosan et al. no prelo) têm atribuído uma origem relacionada a ambiente de complexo de caldeira para o vulcanismo Iricoumé.

A afinidade geoquímica toleítica da Formação Quarenta Ilhas foi inicialmente atribuída por Veiga Jr. et al. (1979), quando individualizou os termos toleíticos de basaltos e gabros alcalinos (Formação Seringa), anteriormente agrupados sob a denominação de Gabro Suretama. Veiga Jr. et al. (1979) obtiveram idades K-Ar (plagioclásio) de $1452 \pm 71 \mathrm{Ma}$ e $1090 \pm 13 \mathrm{Ma}$ para as formações Quarenta Ilhas e Seringa, respectivamente. Os autores correlacionaram o magmatismo da Formação Quarenta Ilhas com o magmatismo toleítico Avanavero. As rochas básicas vinculadas ao magmatismo Avanavero ocorrem como diques e soleiras, intrusivos na sequência sedimentar do Supergrupo Roraima e aflorantes na Guiana, Guiana Francesa, Suriname, Venezuela e norte do estado de Roraima (Hebeda et al. 1973, Norcross et al. 2000, Santos et al. 2002, Nomade et al. 2002). Norcross et al. (2000) obtiveram idade $\mathrm{Pb}-\mathrm{Pb}$ em badeleíta de $1786 \pm 5 \mathrm{Ma}$ para um dique de diabásio da região de Omai (Guiana), o qual os autores relacionaram ao Magmatismo Avanavero. Santos et al. (2002) atribuíram uma idade U-Pb (badeleíta) de $1780 \pm 3 \mathrm{Ma}$ para um diabásio da Formação Quarenta Ilhas, correlacionando-o ao diabásio Crepori, da Província Mineral do Tapajós. As rochas básicas de afinidade toleítica, relacionadas ao Diabásio Crepori (Santos \& Loguércio 1984), possuem idade U-Pb em badeleíta de $1780 \pm 7 \mathrm{Ma}$ (Santos et al. 2002) e são intrusivas em sequência sedimentar siliciclástica (Formação Palmares de Bizzinella et al. 1980 ou Formação Boiuçu de Klein et al. (2001). Dessa forma, Santos et al. (2002) relacionaram ao Magmatismo Crepori as ocorrências de rochas subvulcânicas básicas, com afinidade toleítica, idades em torno de $1,78 \mathrm{Ga}$, e intrusivas em sequências sedimentares.

MÉTODOS O mapeamento geológico e a amostragem foram baseados em mapas geológicos e prospectivos disponibilizados pela companhia mineradora. Foram coletadas em torno de 35 amostras representativas das variações texturais e composicionais da Formação Quarenta Ilhas. As lâminas delgadas foram confeccionadas junto ao Laboratório de Geologia Isotópica da UFRGS. As análises litoquímicas foram realizadas em laboratório comercial seguindo metodologias relacionadas a ICP-OES para elementos maiores, ICP-MS para elementos traço. Os Elementos do Grupo da Platina e Au foram analisados por ICP-MS Fire Assay. O flúor foi analisado segundo a técnica ISE.

Os dados de química mineral foram obtidos em microssonda eletrônica do tipo CAMECA SX-100 do Setor de Mineralogia da Ludwig-Maximilians-Universität München, Alemanha. As condições analíticas para feldspatos e piroxênios consistiram de corrente elétrica de $40 \mathrm{nA}$ com aceleração de voltagem de $15 \mathrm{kv}$ e feixe elétrico de $1 \mu \mathrm{m}$. Para os anfibólios o feixe foi aumen- 
tado para $10 \mu \mathrm{m}$. Os óxidos de Fe-Ti foram analisados sob corrente elétrica de $40 \mathrm{nA}$, aceleração de voltagem de $20 \mathrm{kv}$ e feixe elétrico de $1 \mu \mathrm{m}$. Para cada elemento foram utilizados os seguintes cristais, raias de raios- $\mathrm{X}$ e padrões analíticos: Si- TAP, Ka, wollastonita; Ti- PET, $\mathrm{K} \alpha$, ilmenita; Al- TAP, $\mathrm{K} \alpha$, albita; $\mathrm{Fe}-\mathrm{LIF}, \mathrm{K} \alpha, \mathrm{Fe}_{2} \mathrm{O}_{3}$;

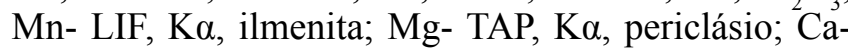
PET, Ka, wollastonita; Na- TAP, K $\alpha$, albita; K- PET, $\mathrm{K} \alpha$, ortoclásio; Cr- LIF, $\mathrm{K} \alpha, \mathrm{Cr}_{2} \mathrm{O}_{3}$; F- PC1, $\mathrm{K} \alpha$, LiF; $\mathrm{Cl}-\mathrm{PET}, \mathrm{K} \alpha$, vanadinita.

\section{GEOLOGIA DA FORMAÇÃO QUARENTA ILHAS}

Ocorrências estudadas e relações de contato As ocorrências relacionadas à Formação Quarenta Ilhas no Distrito Mineiro de Pitinga consistem de corpos subvulcânicos de diabásio, gabro, diorito e quartzo diorito. Três ocorrências são abordadas neste trabalho (Fig. 1): a primeira (ponto A24) consiste de um extenso afloramento ao longo do Rio Pitinga, constituído por gabro a quartzo diorito de textura fanerítica média a grossa. Essa ocorrência foi mapeada por Veiga Jr. et al. (1979) como uma espessa soleira intrusiva na sequência sedimentar da Formação Urupi, segundo estruturas relacionadas à Braquissinclinal de Pitinga. A segunda ocorrência, também mapeada por Veiga Jr. et al. (1979), consiste de blocos e matacões de diabásio com textura fanerítica fina (pontos A87, A88, A89, A90 e A91). No ponto A90 é observado um dique de diabásio de aproximadamente $4,0 \mathrm{~m}$ de espessura, em contato com arenito da Formação Urupi. A terceira ocorrência é identificada em trabalhos prospectivos da mineradora (pontos A94 e A96). Esses litotipos consistem de diabásio de textura fanerítica fina. Uma relação de contato intrusiva entre o diabásio e ignimbritos do Grupo Iricoumé pode ser observada no ponto A94.

Petrografia e Química Mineral A Formação Quarenta Ilhas no Distrito Mineiro de Pitinga pode ser individualizada em dois grupos texturais: rochas com textura fanerítica fina (diabásios) e rochas com textura fanerítica média a grossa (gabros e dioritos). As primeiras afloram em duas regiões: a $\sim 22 \mathrm{~km}$ a leste da Mina Pitinga (pontos A94 e A96); e nas proximidades da usina hidrelétrica ( $\sim 10 \mathrm{~km}$ a sudoeste - pontos A87, A88, A89, A90, A91). Os gabros e dioritos afloram nas margens do Rio Pitinga a $\sim 4 \mathrm{~km}$ a sudeste da usina hidrelétrica (ponto A24).

Os diabásios e gabros são constituídos dominantemente por plagioclásio prismático, augita intersticial a prismática, e óxidos de ferro e titânio. Olivina ocorre de forma subordinada, como grãos subédricos substituídos pseudomorficamente por ferro-saponita. A augita consiste preferencialmente de grãos prismáticos euédricos a subédricos. Nos diabásios onde ocorre olivina, a augita possui forma anédrica a subédrica intersticial (Fig 2a). Óxidos de Fe-Ti consistem de ilmenita prismática em quantidades subordinadas e frequentemente inclusas em magnetita subédrica. Feições de acumulação de augita e plagioclásio prismáticos podem ser observadas localmente em gabros e diabásios. Textura ofítica a subofítica ocorre localmente nas rochas básicas e é caracterizada por grãos anédricos tardios de plagioclásio envolvendo grãos, euédricos de augita (Fig. 2b). Os minerais acessórios consistem de apatita euédrica a subédrica e titanita subédrica.

Dioritos e quartzo dioritos possuem textura fanerítica equigranular grossa constituída dominantemente por plagioclásio, augita e óxidos de Fe-Ti subordinados. Localmente são observados cristais prismáticos alongados de augita. A hornblenda ocorre preferencialmente formando textura coronítica (Fig. 2c). O feldspato alcalino consiste de grãos subédricos, geralmente formando textura micrográfica quando aliado ao quartzo (Fig. 2d). A apatita atinge quantidades varietais ( $>5 \%$ modal) nos dioritos, apresentando hábito prismático acicular.

Os minerais secundários são pouco abundantes e consistem de mica branca, clorita, ferro-saponita, titanita, carbonatos, epidoto e sulfetos. A mica branca é proveniente da sericitização do plagioclásio. Clorita e ferro-saponita são produtos de substituição pseudomórfica de hornblenda e de olivina, respectivamente. A titanita ocorre como produto de alteração dos óxidos de Fe-Ti. Carbonatos, epidoto e sulfetos (pirita e calcopirita) ocorrem localmente como produtos de alteração hidrotermal.

FELDSPATOS O plagioclásio é o feldspato mais abundante e é caracterizado pelo zoneamento composicional, variando de labradorita $\left(\mathrm{An}_{64} \mathrm{Ab}_{35} \mathrm{Or}_{1}\right)$ a andesina e oligoclásio $\left(\mathrm{An}_{18} \mathrm{Ab}_{73} \mathrm{Or}_{9}\right)$ (Fig. 3, Tab. 1). O zoneamento composicional consiste de um aumento, do centro para a borda, de $\mathrm{SiO}_{2}, \mathrm{Na}_{2} \mathrm{O}$ e $\mathrm{K}_{2} \mathrm{O}$, e diminuição em $\mathrm{Al}_{2} \mathrm{O}_{3} \mathrm{e}$ $\mathrm{CaO}$ (Fig. 4). Os conteúdos de $\mathrm{FeO}^{\mathrm{t}}$ variam de $0.28 \%$ a $1.52 \%$ e tendem a diminuir de labradorita para oligoclásio. Núcleos de plagioclásio com composição labradorítica são observados preferencialmente em gabros e diabásios, enquanto os dioritos e quartzo dioritos possuem plagioclásio com núcleos de composição de andesina. Os grãos de plagioclásio das texturas ofíticas e subofiticas possuem composições de andesina a oligoclásio.

$O$ feldspato alcalino ocorre em quantidades em torno de 5\% e invariavelmente possui lamelas de exsolução. As lamelas são preferencialmente caracterizadas por composições que variam de $\mathrm{Ab}_{2} \mathrm{Or}_{98}$ a $\mathrm{Ab}_{99} \mathrm{Or}_{1}$. No entanto, algumas lamelas possuem composição de sanidina desde $\mathrm{Ab}_{60} \mathrm{Or}_{40}$ até $\mathrm{Ab}_{12} \mathrm{Or}_{88}$, sugerindo exsolução parcial dos componentes ortoclásio e albita.

OLIVINA (FERRO-SAPONITA) Os grãos de olivina estão invariavelmente substituídos pseudomorficamente por minerais secundários. A geometria desta fase indica que esta ocorria como subédrica em quantidades subordinadas, essencialmente nos diabásios onde a augita é intersticial (amostras A87, A89 e A90). Os resultados de química mineral indicam conteúdos de $\mathrm{SiO}_{2}$ em torno de $33,5 \%, \mathrm{Al}_{2} \mathrm{O}_{3}$ próximos a $12,35 \%, \mathrm{FeO}$ de $20,63 \%$ a 25,55\%, e MgO entre 17,36\% e 17,97\%. Os conteúdos de $\mathrm{Na}_{2} \mathrm{O}, \mathrm{CaO}$ e $\mathrm{K}_{2} \mathrm{O}$ são inferiores a $1 \%$ (Tab. 2). O fechamento das análises é próximo a $88,0 \%$, e sugere moderado conteúdo de fluidos $\left(\mathrm{H}_{2} \mathrm{O}, \mathrm{OH}\right)$. Essa composição sugere relação com mineral do grupo das esmectitas do tipo ferro-saponita. 

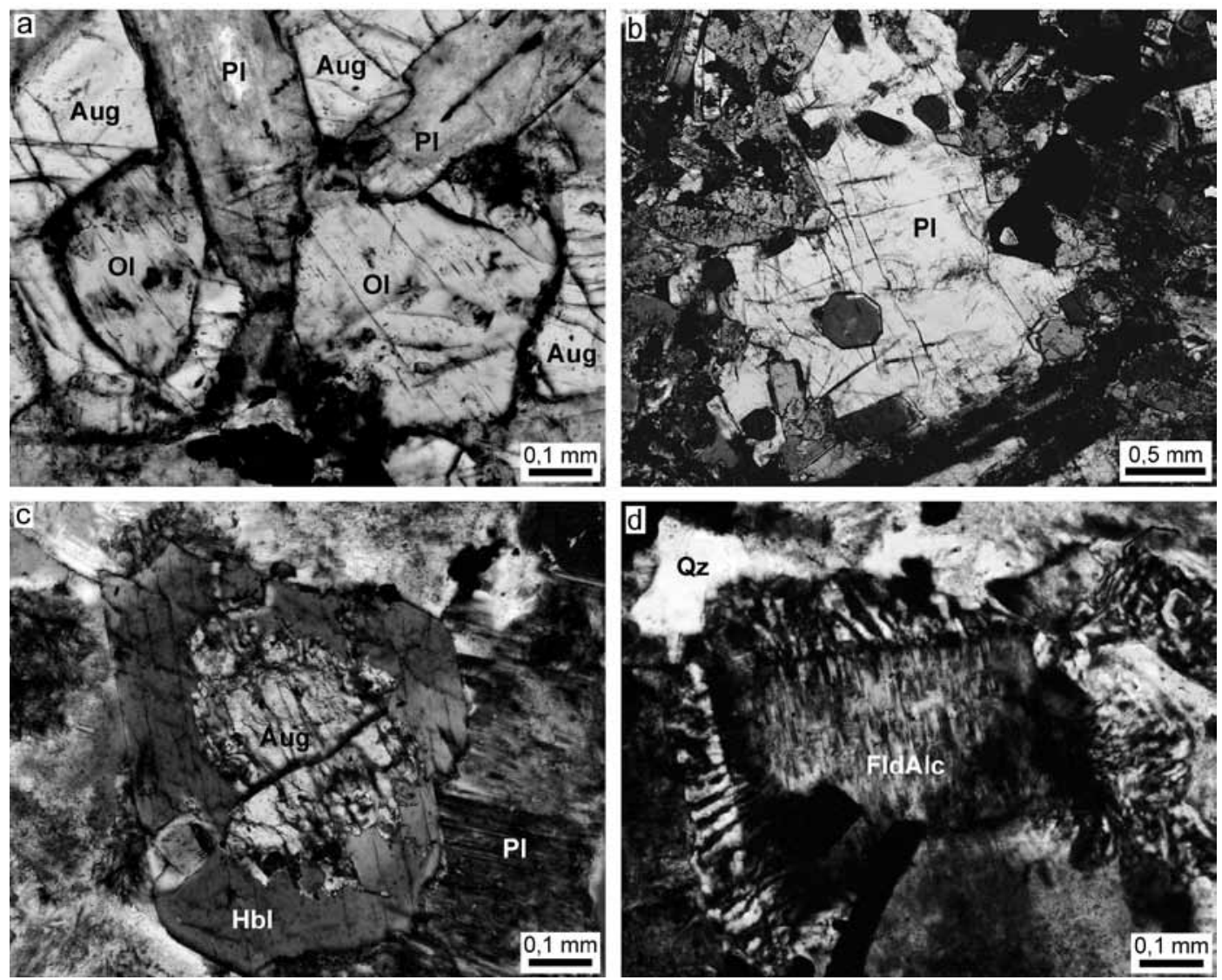

Figura 2 - Feições petrográficas das rochas básicas e intermediárias da Formação Quarenta Ilhas (nicóis cruzados). a) diabásio com plagioclásio euédrico, olivina subédrica substituida por saponita, e augita intersticial; b) diabásio com textura subofítica; c) diorito com textura coronítica; d) quartzo diorito com intercrescimento micrográfico e feldspato alcalino pertítico. Abreviações: Pl-plagioclásio; Aug-augita; Ol-olivina, Hbl-hornblenda; FldAlc-feldspato alcalino; Qz-quartzo.

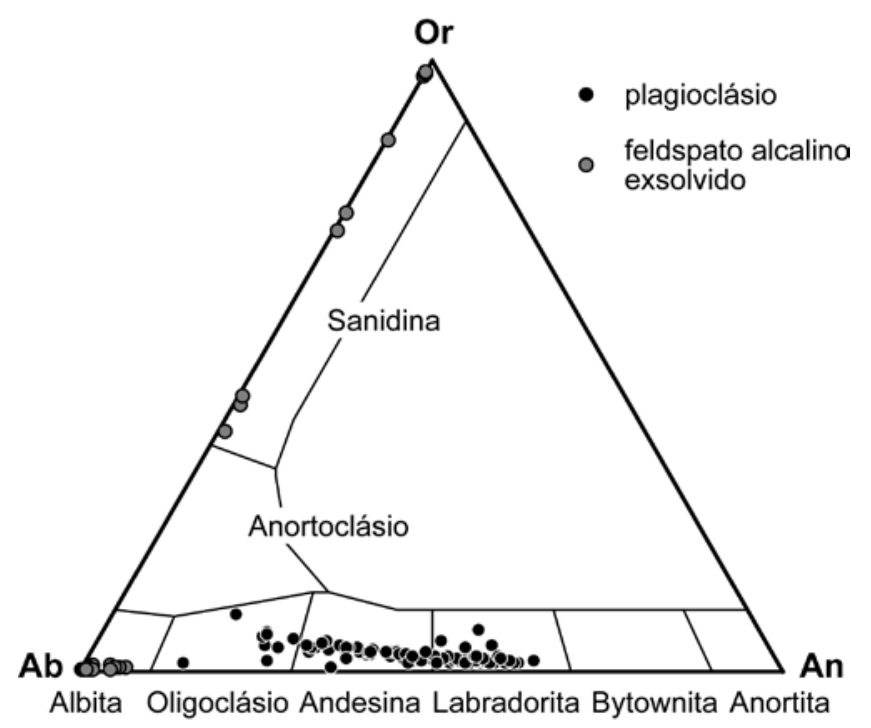

Figura 3 - Diagrama ternário de classificação dos feldspatos da Formação Quarenta Ilhas.
CLINOPIROXÊNIOS Os clinopiroxênios são abundantes nas rochas básicas e consistem dominantemente de grãos subédricos a euédricos prismáticos. Nos diabásios onde ocorre olivina, o clinopiroxênio possui formas anédricas intersticiais. O pleocroismo é fraco e varia de incolor a castanho claro rosado e incolor a verde claro.

Nas rochas intermediárias os clinopiroxênios são menos abundantes e possuem pleocroismo fraco, de incolor a verde claro. Consistem geralmente de grãos subédricos prismáticos e, localmente, de prismas euédricos alongados, atingindo até $1,2 \mathrm{~cm}$. A textura coronítica é comum nas rochas intermediárias, caracterizadas por hornblenda envolvendo clinopiroxênio.

As fórmulas estruturais são calculadas segundo a nomenclatura de Morimoto (1988) utilizando o programa Minpet 2.0. Os valores de $\mathrm{Fe}^{3+}$ são obtidos pelo método de balanço de cargas, na base de 6 oxigênios. Os clinopiroxênios são cálcicos e estão classificados dominantemente como augita, com diopsídio em quantidades subordinadas (Fig. 5). O diopsídio possui composições próximas a $\mathrm{Wo}_{45} \mathrm{En}_{40} \mathrm{Fs}_{15}$ e ocorre somente em diabásios menos diferenciados. A augita de rochas básicas possui 
Tabela 1 - Análises representativas de feldspatos da Formação Quarenta Ilhas no Distrito Mineiro de Pitinga.

\begin{tabular}{|c|c|c|c|c|c|c|c|c|c|c|c|c|c|c|c|c|}
\hline Amostra & A $89 b$ & $\mathrm{~A} 89 \mathrm{~b}$ & A $89 b$ & A89b & $\mathrm{A} 24 \mathrm{a}$ & A87a & A88a & A88a & A96a & A96a & A96a & A96a & $\mathrm{A} 24 \mathrm{z}$ & A24h & A24h & $\mathrm{A} 24 \mathrm{z}$ \\
\hline Análise & 09 & 20 & 02 & 16 & 04 & 05 & 05 & 25 & 01 & 04 & 08 & 18 & 09 & 09 & 17 & 04 \\
\hline Tipo & $\mathrm{br}$ & $\mathrm{br}$ & labr & labr & and & and & and & and & olig & olig & olig & olig & ort & san & san & alb \\
\hline Posição* & ntro & ntro & ntro & centro & entro & centro & centro & orda & orda & borda & orda & borda & centro & centro & centro & centro \\
\hline \multicolumn{17}{|l|}{$\%$ em peso } \\
\hline $\mathrm{SiO}_{2}$ & 03 & 56 & 48 & 19 & 83 & 6,75 & 8,59 & 0,99 & 52,67 & 62,71 & 2,63 & 61,37 & 54,78 & 66,34 & 67,58 & 69,18 \\
\hline $\mathrm{TiO}_{2}$ & 03 & 01 & 04 & 04 & 0,06 & 0,03 & 0,02 & 0,01 & 04 & 0,00 &, 00 &, 00 & 0,00 & 0,00 & 0,00 & 0,00 \\
\hline $\mathrm{Al}_{2} \mathrm{O}_{3}$ &, 25 & 27,55 & 29,02 & 24,90 & 26,14 & 26,46 & 25,17 & 23,72 & 22,61 & 22,75 & 22,88 & 23,50 & 17,68 & 17,61 & 17,82 & 18,45 \\
\hline & 0,79 & 09 & 0,65 & & 0,62 & 0,71 & 0,62 & 45 & 0,39 & 0,43 & 0,42 & 0,58 & 0,00 & 0,15 & 0,17 & 0,04 \\
\hline & & & & & & 00 & & & & & & &, 00 & 00 & 00 & 02 \\
\hline & & & & & & 10 & & & & & & & 0,00 &, 00 &, 00 & 0,02 \\
\hline & ,99 & ,73 & 2,98 &, 57 & 53 & 10,00 & 8,28 & & & 5,15 & 88 & J & 0,01 &, 15 & 0,21 & 0,17 \\
\hline & & & & & & 82 & & & & & & & 0,18 & 96 &, 78 & 11,92 \\
\hline${ }_{2} \mathrm{O}$ & 30 & 28 & 25 & 26 & 0,42 & 36 & 0,59 & 0,78 & 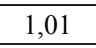 & 0,73 & 05 & 92 & 16,33 & 1,92 & 6,84 & 0,05 \\
\hline Soma & 9,71 & 100,26 & 0,89 & 100,39 & 100,96 & 100,31 & 100,05 & 99,99 & 100,26 & 100,18 & 99,97 & 100,19 & 98,99 & 99,14 & 99,41 & 99,85 \\
\hline \multicolumn{17}{|l|}{ a.p.f.u. } \\
\hline $\mathrm{Si}$ & ,004 & & 9,657 & 10,451 & 10,329 & 10,222 & 10,533 & 10,901 & 11,142 & 11,143 & 11,147 & 10,953 & 12,093 & 2,16 & 12,151 & 12,108 \\
\hline $\mathrm{Al}$ & 834 & 5,887 & 6,171 & & 5,498 & 5,613 & 5,329 & 4,993 & & 4,761 & 4,796 & 4,939 & 3,887 & 801 & 3,773 & 3,803 \\
\hline $\mathrm{Ti}$ & 004 & 001 & 005 & & & 0,004 & 0,003 & 0,001 & & 000 &, 000 & 000 & 0,000 &, 000 &, 000 &, 000 \\
\hline $\mathrm{Fe}^{2+}$ & 0,120 & 0,165 & 0,098 & 0,167 & 0,093 & 0,107 & 0,093 & 0,067 & 0,058 & 0,064 & 0,063 & 0,087 & 0,000 & 0,023 &, 026 & 006 \\
\hline & 002 & & 0,006 & & & 0,000 & 0,002 & & & 0,003 & & & 0,000 & 0,000 &, 000 & 0,003 \\
\hline & & & & & & & & & & 0,000 & & & 0,000 & 0,000 &, 000 & 0,005 \\
\hline & 141 & 2,280 & 2,511 & & 1,824 & 1,930 & 1,595 & 1,216 & & 0,980 & 0,931 & 1,128 & 0,002 & 0,029 & 0,040 & 0,032 \\
\hline $\mathrm{Na}$ & 1,819 & 1,699 & 1,509 & & 2,178 & 2,033 & 2,318 & 2,634 & 2,923 & 2,870 & 2,775 & 2,710 & 0,065 & 1,052 & 2,364 & 4,045 \\
\hline $\mathrm{K}$ & 070 & 0,065 & 0,058 & & 0,096 & & & & & 0,165 & 0,238 & & 3,889 & 2,787 & 1,569 & 0,011 \\
\hline $\begin{array}{l}\text { Soma } \\
\text { cátions }\end{array}$ & 20,013 & 20,027 & 20,026 & 19,636 & 20,042 & 20,019 & 20,019 & 19,998 & 20,055 & 19,986 & 19,956 & 20,029 & 19,936 & 19,852 & 19,923 & 20,013 \\
\hline $\mathrm{Ab}$ & 45,10 & 42,00 & 37,00 & 38,10 & 53,10 & 50,20 & 57,30 & 65,40 & 71,20 & 71,50 & 70,40 & 67,00 & 1,60 & 27,20 & 59,50 & 98,90 \\
\hline An & 53,10 & 56,40 & 61,60 & 60,30 & 44,50 & 47,70 & 39,40 & 30,20 & 23,20 & 24,40 & 23,60 & 27,90 & 0,10 & 0,70 & 1,00 & 0,80 \\
\hline Or & 1,70 & 1,60 & 1,40 & 1,60 & 2,30 & 2,10 & 3,30 & 4,40 & 5,60 & 4,10 & 6,00 & 5,20 & 98,30 & 72,10 & 39,50 & 0,30 \\
\hline
\end{tabular}

Observações: fórmulas estruturais calculadas na base de 32 oxigênios; ferro analisado como $\mathrm{Fe}^{2+}$

* posição do ponto analisado em relação à proximidade do centro ou da borda do cristal.

Abreviações: a.p.f.u.: átomos por fórmula unitária; labr: labradorita; and: andesina; olig: oligoclásio; ort: ortoclásio; san: sanidina; alb: albita.

um trend evolutivo caracterizado pela diminuição do componente wolastonita (Wo) de $44 \%$ a $35 \%$, seguido do aumento do componente ferrosilita (Fs) de $16 \%$ a $31 \%$. Os conteúdos do componente enstatita (En) diminuem de $44 \%$ a $33 \%$ em direção aos cristais de augita dos diabásios mais diferenciados. A augita das rochas intermediárias segue esse trend evolutivo, com aumento de Wo de $38 \%$ a $41 \%$, acompanhado do aumento de Fs de $31 \%$ a $38 \%$ e consequente diminuição de En de $29 \%$ a $21 \%$. O trend evolutivo dos clinopiroxênios, desde diabásios até quartzo dioritos, segue a tendência usual de cristalização observada por Deer et al. (1992), caracterizada pela diminuição inicial de $\mathrm{CaO}$, seguida do aumento de $\mathrm{FeO}^{\mathrm{t}}$, diminuição de $\mathrm{MgO}$ e sutil aumento de $\mathrm{CaO}$ nos cristais de augita mais diferenciados. (Tab. 3). Com base em seus conteúdos relativos, é possível individualizar quatro grupos de clinopiroxênios:

- Grupo I - diopsídio e augita com alto $\mathrm{CaO}$ e baixo $\mathrm{FeO}^{\mathrm{t}}$ e $\mathrm{TiO}_{2}$ (diabásio $\mathrm{A} 89 \mathrm{a}$ );

- Grupo II - augita com alto $\mathrm{TiO}_{2}$ e $\mathrm{MgO}$, moderado $\mathrm{CaO}$ e baixo $\mathrm{FeO}^{\mathrm{t}}$ (diabásios $\mathrm{A} 87 \mathrm{a}$ e $\mathrm{A} 88 \mathrm{a}$, e gabro A24a);

- Grupo III - augita com moderado $\mathrm{FeO}^{t}$ e baixo $\mathrm{CaO}$ (diabásio A96a);

- Grupo IV - augita com alto $\mathrm{FeO}^{t}$ e baixo $\mathrm{MgO}$,

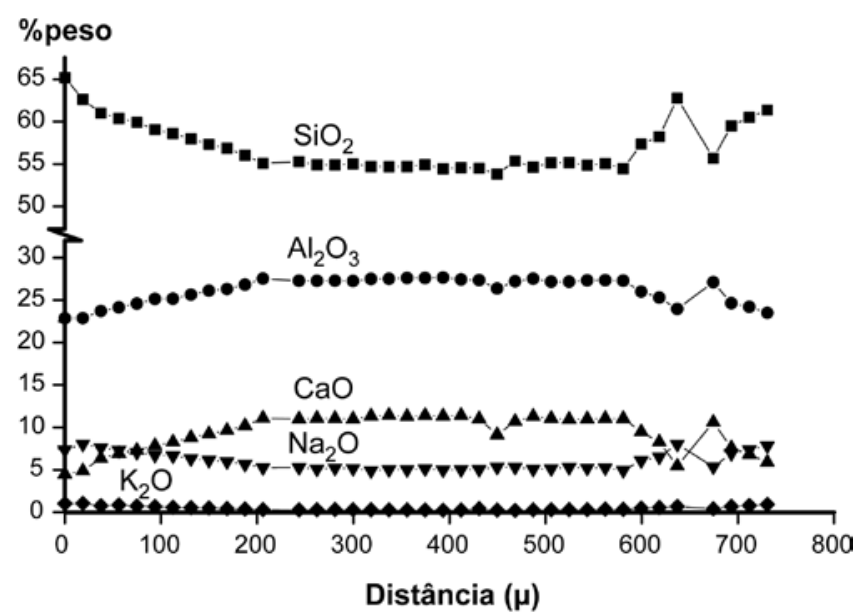

Figura 4 - Seção borda-centro-borda representativa do zoneamento composicional do plagioclásio em diabásio (amostra A88a) da Formação Quarenta Ilhas no Distrito Mineiro de Pitinga.

$\mathrm{TiO}_{2}$ e $\mathrm{Al}_{2} \mathrm{O}_{3}$ (dioritos $\mathrm{A} 24 \mathrm{~h}$ e $\mathrm{A} 24 \mathrm{z}$ ).

A distribuição de Si e $\mathrm{Al}$ no sítio $\mathrm{T}$, nos quatro grupos, define uma correlação negativa. A augita dos 
Tabela 2 - Análises representativas de ferro-saponita da Formação Quarenta Ilhas no Distrito Mineiro de Pitinga.

\begin{tabular}{l|c|c|c|c|c|c}
\hline Amostra & A87a & A87a & A87a & A87a & A87a & A87a \\
\hline Análise & 01 & 07 & 09 & 20 & 24 & 33 \\
\hline Tipo & Fe-sap & Fe-sap & Fe-sap & Fe-sap & Fe-sap & Fe-sap \\
\hline Posição* & centro & centro & centro & centro & centro & centro \\
\hline \% em peso & & & & & & \\
\hline $\mathrm{SiO}_{2}$ & 34,28 & 33,95 & 33,53 & 33,20 & 33,75 & 32,56 \\
\hline $\mathrm{TiO}_{2}$ & 0,02 & 0,03 & 0,01 & 0,02 & 0,03 & 0,00 \\
\hline $\mathrm{Al}_{2} \mathrm{O}_{3}$ & 11,51 & 13,39 & 13,48 & 13,86 & 11,39 & 13,37 \\
\hline $\mathrm{FeO}_{\mathrm{Cr}} \mathrm{O}_{3}$ & 24,66 & 20,98 & 21,32 & 21,05 & 25,55 & 22,61 \\
\hline $\mathrm{MnO}$ & 0,00 & 0,00 & 0,07 & 0,06 & 0,00 & 0,00 \\
\hline $\mathrm{MgO}$ & 0,15 & 0,48 & 0,48 & 0,52 & 0,18 & 0,36 \\
\hline $\mathrm{CaO}$ & 17,68 & 17,72 & 18,48 & 18,91 & 17,41 & 18,70 \\
\hline $\mathrm{Na} \mathrm{O}_{2} \mathrm{O}$ & 0,15 & 0,52 & 0,30 & 0,46 & 0,19 & 0,20 \\
\hline $\mathrm{K}_{2} \mathrm{O}$ & 0,04 & 0,06 & 0,06 & 0,06 & 0,05 & 0,04 \\
\hline $\mathrm{Soma}$ & 0,12 & 0,01 & 0,02 & 0,01 & 0,09 & 0,01 \\
\hline a.p.f.u. & 88,62 & 87,15 & 87,76 & 88,16 & 88,66 & 87,85 \\
\hline $\mathrm{Si}$ & 5,613 & 5,608 & 5,512 & 5,439 & 5,545 & 5,371 \\
\hline $\mathrm{Al}$ & 2,221 & 2,607 & 2,611 & 2,676 & 2,205 & 2,599 \\
\hline $\mathrm{Ti}$ & 0,003 & 0,003 & 0,001 & 0,002 & 0,004 & 0,000 \\
\hline $\mathrm{Fe}{ }^{2+}$ & 3,376 & 2,898 & 2,930 & 2,883 & 3,509 & 3,118 \\
\hline $\mathrm{Cr}$ & 0,000 & 0,000 & 0,009 & 0,008 & 0,000 & 0,000 \\
\hline $\mathrm{Mn}$ & 0,017 & 0,055 & 0,055 & 0,059 & 0,021 & 0,041 \\
\hline $\mathrm{Mg}$ & 4,316 & 4,365 & 4,529 & 4,618 & 4,264 & 4,599 \\
\hline $\mathrm{Ca}$ & 0,026 & 0,092 & 0,053 & 0,081 & 0,033 & 0,035 \\
\hline $\mathrm{Na}$ & 0,011 & 0,021 & 0,020 & 0,020 & 0,017 & 0,012 \\
\hline $\mathrm{K}$ & 0,024 & 0,003 & 0,005 & 0,003 & 0,019 & 0,003 \\
\hline $\mathrm{Soma}$ cátions & 15,608 & 15,652 & 15,726 & 15,789 & 15,618 & 15,778 \\
\hline & & & & & & \\
\hline & & & & & & \\
\hline $\mathrm{Mg}$ & & & & & \\
\hline
\end{tabular}

Observações: fórmulas estruturais calculadas na base de 24 oxigênios; ferro analisado como $\mathrm{Fe}^{2+}$

* posição do ponto analisado em relação à proximidade do centro ou da borda do cristal. Abreviações: a.p.f.u.: átomos por fórmula unitária; Fe-sap: ferro-saponita.

grupos I e III possui conteúdos de ${ }^{\mathrm{T}} \mathrm{Al}$ intermediários, enquanto no Grupo II variam de elevados a intermediários. O Grupo IV possui baixos conteúdos de ${ }^{\mathrm{T}} \mathrm{Al} \mathrm{e}$ consequentemente elevados conteúdos de ${ }^{\mathrm{T}} \mathrm{Si}$ (Fig. 6a). No sítio M1, Fe e Mg se correlacionam negativamente, com conteúdos elevados de ${ }^{\mathrm{Ml}} \mathrm{Mg}$ em augita dos grupos I, II e III. A augita do Grupo IV possui elevados conteúdos de ${ }^{\mathrm{Ml}} \mathrm{Fe}^{2+}$, e melhor se correlaciona com a augita do Grupo III (Fig. 6b). A correlação negativa de Ca e Fe no sítio M2 é caracterizada pelos elevados conteúdos de ${ }^{\mathrm{M} 2} \mathrm{Ca}$ em cristais de augita do Grupo I, baixos na augita do Grupo III e intermediários nos grupos II e IV (Fig. 6c). As principais substituições catiônicas observadas nos quatro grupos consistem de trocas simples do tipo $\mathrm{Si} \leftrightarrow \mathrm{Al}$ no sítio $\mathrm{T}, \mathrm{Mg} \leftrightarrow \mathrm{Fe}^{2+}$ no sítio $\mathrm{M} 1 \mathrm{e}$ $\mathrm{Fe}^{2+} \leftrightarrow \mathrm{Ca}$ no sítio M2. Os valores médios de $\mathrm{Fe}^{3+}$ variam de 0,061apfu a 0,072apfu em augita dos grupos I, II e III, algumas vezes excedendo 0,1 apfu na augita dos grupos I e II. Na augita do Grupo II os conteúdos de $\mathrm{Fe}^{3+}$ atingem 0,136apfu, frequentemente ocupando o sítio $\mathrm{T}$. Os conteúdos ${ }^{\mathrm{M} 2} \mathrm{Mn}$ aumentam significativamente da augita dos grupos I, II e III para a augita do Grupo IV, com valores médios entre 0,010 e 0,012apfu para 0,026apfu no Grupo IV.

A distribuição dos conteúdos de ${ }^{\mathrm{T}} \mathrm{Al},{ }^{\mathrm{Ml}} \mathrm{Ti} \mathrm{e}^{\mathrm{Fe}}{ }^{3+} /$

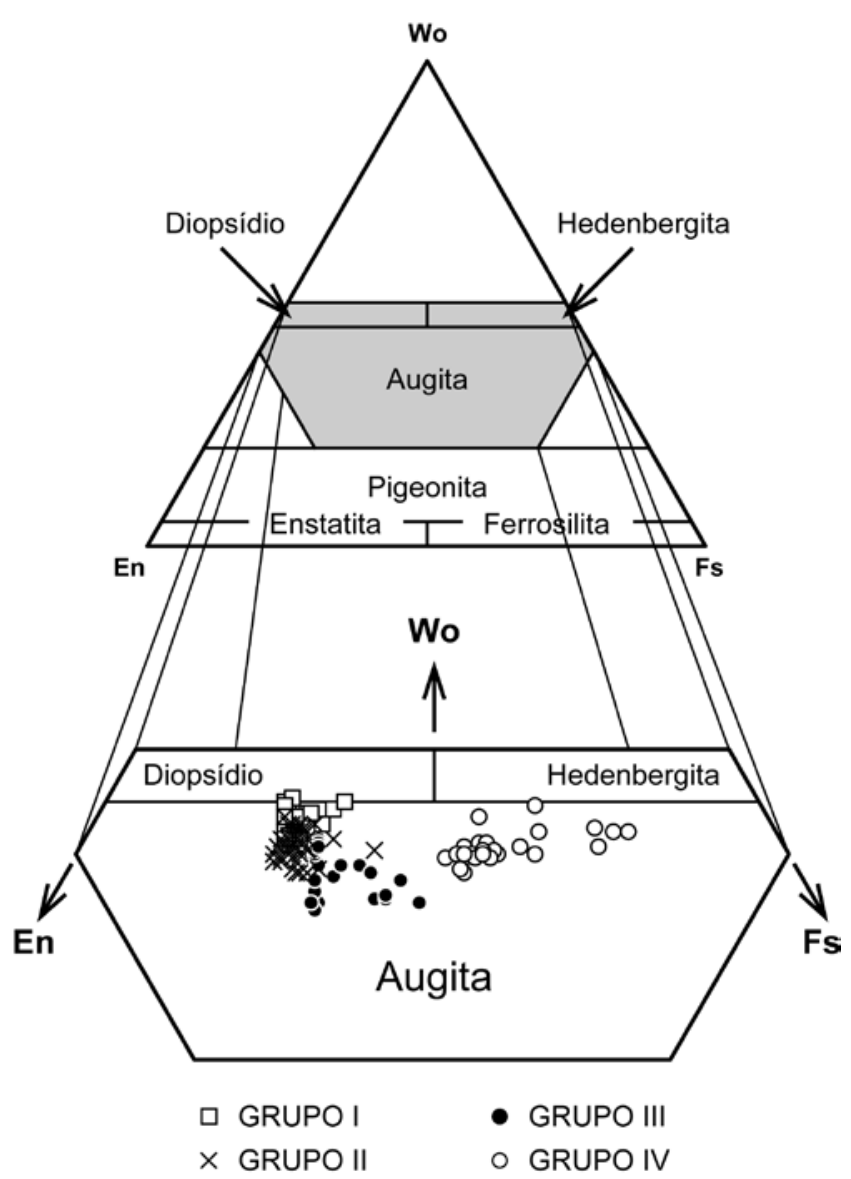

Figura 5 - Diagrama de Morimoto (1988) para classificação dos clinopiroxênios cálcicos da Formação Quarenta Ilhas.

$\left(\mathrm{Fe}^{3+}+\mathrm{Fe}^{2+}\right)_{\text {total }}$, quando comparados ao índice $\mathrm{nMg}(\mathrm{nMg}$ $\left.=\mathrm{Mg} /\left(\mathrm{Mg}+\mathrm{Fe}^{2+}\right)\right)$, ilustram as particularidades composicionais observadas nos grupos I, II, III e IV (Fig. 7a,b,c). Os conteúdos de ${ }^{\mathrm{T}} \mathrm{Al}$ e $\mathrm{Fe}^{3+} /\left(\mathrm{Fe}^{3+}+\mathrm{Fe}^{2+}\right)_{\text {total }}$ da augita dos grupos I e II apresentam padrão de distribuição paralelos entre si, enquanto o padrão de ${ }^{\mathrm{M} 1} \mathrm{Ti}$ das augitas do grupo II é significativamente mais elevado que o do grupo I. Os cristais de augita dos grupos III e IV apresentam correlação entre si quanto aos conteúdos de ${ }^{\mathrm{T}} \mathrm{Al} \mathrm{e}^{\mathrm{Ml}} \mathrm{Ti}$ em relação a nMg. No entanto, a distribuição de $\mathrm{Fe}^{3+} /\left(\mathrm{Fe}^{3+}+\mathrm{Fe}^{2+}\right)$ total em cristais de augita do grupo III sugere que parte se correlaciona com a augita do Grupo IV e parte acompanha o padrão da augita dos grupos I e II.

ANFIBÓLIOS A hornblenda ocorre em dioritos e gabro dioritos, como constituinte da textura coronítica e como grãos isolados. A hornblenda de textura coronítica possui terminações subédricas a euédricas, enquanto os grãos isolados tendem a possuir formas euédricas. O pleocroismo varia de castanho claro a verde claro e verde escuro.

A composição da hornblenda caracteriza-se por conteúdos de $\mathrm{SiO}_{2}$ que variam entre $44,21 \%$ e $51,94 \%$, $\mathrm{Al}_{2} \mathrm{O}_{3}$ entre $0,93 \%$ e $6,33 \%$, altos conteúdos de $\mathrm{FeO}^{\mathrm{t}}$ (entre 22,97\% e 29,48\%), e baixos de $\mathrm{MgO}$ (de 3,99\% 
Tabela 3 - Análises representativas de piroxênios da Formação Quarenta Ilhas no Distrito Mineiro de Pitinga.

\begin{tabular}{|c|c|c|c|c|c|c|c|c|c|c|c|c|c|c|c|c|}
\hline Amostra & A $89 b$ & A89b & $A 89 b$ & A89b & A24a & A87a & A88a & A88a & A96a & A96a & A96a & A96a & A24h & A24h & A24z & A24z \\
\hline Análise & 09 & 20 & 02 & 16 & 04 & 05 & 05 & 25 & 01 & 04 & 08 & 18 & 03 & 05 & 01 & 10 \\
\hline Grupo & I & $\mathrm{I}$ & $\mathrm{I}$ & I & II & II & II & II & III & III & III & III & IV & IV & IV & IV \\
\hline Tipo & diop & diop & aug & aug & aug & aug & aug & aug & aug & aug & aug & aug & aug & aug & aug & aug \\
\hline Posição* & centro & centro & centro & centro & centro & centro & centro & centro & centro & centro & centro & centro & centro & centro & centro & borda \\
\hline \multicolumn{17}{|l|}{$\%$ em peso } \\
\hline $\mathrm{SiO}_{2}$ & 50,97 & 53,72 & 50,85 & 51,57 & 50,33 & 50,71 & 51,03 & 50,22 & 49,99 & 50,15 & 50,07 & 50,15 & 50,24 & 50,45 & 51,01 & 50,79 \\
\hline $\mathrm{TiO}_{2}$ & 0,34 & 0,03 & 0,36 & 0,25 & 1,10 & 0,88 & 0,78 & 0,85 & 0,37 & 0,30 & 0,42 & 0,42 & 0,24 & 0,26 & 0,16 & 0,22 \\
\hline $\mathrm{Al}_{2} \mathrm{O}_{3}$ & 3,01 & 0,47 & 2,97 & 2,30 & 2,84 & 3,31 & 2,23 & 2,30 & 2,14 & 1,55 & 3,60 & 3,44 & 0,83 & 0,95 & 0,55 & 0,88 \\
\hline $\mathrm{FeO}$ & 9,29 & 9,54 & 10,45 & 9,42 & 11,74 & 10,73 & 10,60 & 10,74 & 16,42 & 18,44 & 12,96 & 12,04 & 19,66 & 18,08 & 21,02 & 18,46 \\
\hline $\mathrm{Cr}_{2} \mathrm{O}_{3}$ & 0,00 & 0,01 & 0,01 & 0,00 & 0,03 & 0,00 & 0,01 & 0,00 & 0,00 & 0,02 & 0,37 & 0,17 & 0,02 & 0,00 & 0,02 & 0,03 \\
\hline $\mathrm{MnO}$ & 0,33 & 0,32 & 0,26 & 0,34 & 0,37 & 25 & 0,32 & 0,40 & 0,40 & 0,48 & 0,30 & 0,25 & 0,78 & 0,78 &, 83 & 0,73 \\
\hline $\mathrm{MgO}$ & 3,84 & 14,02 & 14,21 & 14,21 & 14,68 & 13,62 & 15,14 & 14,86 & 12,74 & 11,47 & 14,10 & 13,38 & 8,36 & 9,92 & 7,46 & 9,44 \\
\hline $\mathrm{CaO}$ & 22,13 & 22,53 & 20,39 & 21,16 & 18,60 & 20,06 & 19,58 & 20,07 & 17,08 & 16,91 & 17,07 & 19,32 & 19,14 & 18,81 & 18,78 & 18,71 \\
\hline $\mathrm{Na}_{2} \mathrm{O}$ & 0,36 & 0,18 & 0,39 & 0,36 & 0,39 & 0,39 & 0,32 & 0,37 & 0,28 & 0,30 & 0,35 & 0,37 & 0,29 & 0,31 & 0,33 & 0,25 \\
\hline $\mathrm{K}_{2} \mathrm{O}$ & 0,00 & 0,00 & 01 & 0,00 & 0,00 & 00 & 0,00 & 0,00 & 0,00 & 0,02 & 0,01 & 0,02 & 0,00 & 0,00 & 0,00 & 0,00 \\
\hline Soma & 100,27 & \begin{tabular}{|l|}
100,82 \\
\end{tabular} & 9,90 & 99,62 & 100,08 & 99,95 & 100,01 & 99,81 & 99,42 & 99,65 & 99,25 & 99,56 & 99,57 & 99,56 & 100,17 & 99,51 \\
\hline \multicolumn{17}{|l|}{ a.p.f.u. } \\
\hline \multicolumn{17}{|l|}{ Sítio T } \\
\hline $\mathrm{Si}$ & 1,890 & 1,991 & 1,894 & 1,925 & 1,878 & 1,896 & 1,898 & 1,873 & 1,910 & 1,931 & 1,889 & 1,887 & 1,969 & 1,958 & 2,001 & 1,979 \\
\hline $\mathrm{Al}^{\mathrm{IV}}$ & 0,110 & 0,009 & 0,106 & 0,075 & 0,122 & 0,104 & 0,098 & 0,101 & 0,090 & 0,069 & 0,111 & 0,113 & 0,031 & 0,042 & 0,000 & 0,021 \\
\hline $\mathrm{Fe}^{3+}$ & 000 & 0,000 & 0,000 & 0,000 & 0,000 & 0,000 & 0,005 & 0,026 & 0,000 & 0,000 & 0,000 & 0,000 & 0,000 & 0,000 & 0,000 & 0,000 \\
\hline Soma sítio T & 2,000 & 2,000 & 2,000 & 2,000 & 2,000 & 2,000 & 2,001 & 2,000 & & 2,000 & 2,000 & 2,000 & 2,000 & 2,000 & & 2,000 \\
\hline \multicolumn{17}{|l|}{ Sítio M1 } \\
\hline $\mathrm{Al}^{\mathrm{VI}}$ & 012 & 0,023 & 0,000 & 0,164 & 0,124 & 0,000 & 0,089 & 0,103 & 0,070 & 0,071 & 0,033 & 0,073 & 0,085 & 0,033 & 0,063 & 0,054 \\
\hline $\mathrm{Ti}$ & 004 & 0,003 & 0,001 & 0,001 & 0,000 & 0,001 & 0,005 & 0,000 & 0,002 & 0,000 & 0,007 & 0,002 & 0,000 & 0,006 & 0,000 & 0,005 \\
\hline $\mathrm{Fe}^{3+}$ & 0,510 & 0,342 & 0,724 & 0,504 & 0,406 & 0,803 & 0,650 & 0,713 & 0,546 & 0,507 & 0,524 & 0,340 & 0,475 & 0,481 & 0,301 & 0,280 \\
\hline $\mathrm{Fe}^{2+}$ & 0,059 & 0,055 & 0,030 & 0,013 & 0,012 & 0,019 & 0,011 & 0,015 & 0,002 & 0,008 & 0,024 & 0,016 & 0,008 & 0,000 & 0,041 & 0,014 \\
\hline $\mathrm{Cr}$ & 355 & 1,333 & & 1,168 & 1,491 & 1,939 & 1,105 & 0,947 & 1,142 & 1,202 & 1,725 & 1,638 & 1,296 & 0,923 & 1,897 & 1,290 \\
\hline $\mathrm{Mg}$ & 2,997 & 3,173 & 2,318 & 3,007 & 2,884 & 2,171 & 3,006 & 3,101 & 3,036 & 3,077 & 2,621 & 2,834 & 3,004 & 3,271 & 2,577 & 3,124 \\
\hline $\begin{array}{l}\text { Soma sítio } \\
\text { M1 }\end{array}$ & 5,001 & 5,000 & 5,000 & 5,000 & 5,000 & 5,000 & 5,001 & 5,000 & 4,999 & 5,000 & 5,000 & 5,000 & 5,000 & 5,001 & 5,001 & 5,000 \\
\hline \multicolumn{17}{|l|}{ Sítio M2 } \\
\hline $\mathrm{Mg}$ & 0,000 & 0,000 & 0,000 & 0,000 & 0,000 & 0,000 & 0,000 & 0,000 & 0,000 & 0,000 & 0,000 & 0,000 & 0,000 & 0,000 & 0,000 & 0,000 \\
\hline $\mathrm{Fe}^{2+}$ & 0,084 & 0,082 & 0,149 & 0,117 & 0,217 & 0,160 & 0,187 & 0,159 & 0,267 & 0,263 & 0,274 & 0,185 & 0,148 & 0,169 & 0,157 & 0,176 \\
\hline $\mathrm{Mn}$ & 0,010 & 0,010 & 0,008 & 0,011 & 0,012 & 0,008 & 0,010 & 0,013 & 0,013 & 0,016 & 0,010 & 0,008 & 0,026 & 0,026 & 0,028 & 0,024 \\
\hline $\mathrm{Ca}$ & 879 & 0,895 & 0,814 & 0,846 & 0,743 & 0,803 & 0,780 & 0,802 & 0,699 & 0,698 & 0,690 & 0,779 & 0,804 & 0,782 & 0,789 & 0,781 \\
\hline $\mathrm{Na}$ & 0,026 & 0,013 & 0,028 & 0,026 & 0,028 & 0,028 & 0,023 & 0,027 & 0,021 & 0,022 & 0,026 & 0,027 & 0,022 & 0,023 & 0,025 & 0,019 \\
\hline $\mathrm{K}$ & 0,000 & 0,000 & 0,000 & 0,000 & 0,000 & 0,000 & 0,000 & 0,000 & 0,000 & 0,001 & 0,000 & 0,001 & 0,000 & 0,000 & 0,000 & 0,000 \\
\hline $\begin{array}{l}\text { Soma sítio } \\
\text { M2 }\end{array}$ & 0,999 & 1,000 & 0,999 & 1,000 & 1,000 & 0,999 & 1,000 & 1,001 & 1,000 & 1,000 & 1,000 & 1,000 & 1,000 & 1,000 & 0,999 & 1,000 \\
\hline Soma cátions & 4,000 & 4,000 & 4,000 & 4,000 & 4,000 & 4,000 & 4,000 & 4,000 & 4,000 & 4,000 & 4,000 & 3,999 & 4,000 & 4,000 & 4,000 & 4,000 \\
\hline Wo & 45,26 & 45,30 & 42,02 & 43,58 & 38,37 & 42,16 & 39,82 & 40,59 & 35,63 & 35,49 & 36,29 & 40,65 & 40,96 & 39,73 & 40,63 & 39,95 \\
\hline En & 39,38 & 39,22 & 40,75 & 40,72 & 42,13 & 39,83 & 42,84 & 41,82 & 36,98 & 33,50 & 41,71 & 39,17 & 24,89 & 29,16 & 22,46 & 28,05 \\
\hline Fs & 15,36 & 15,48 & 17,23 & 15,70 & 19,51 & 18,02 & 17,34 & 17,59 & 27,40 & 31,01 & 22,01 & 20,19 & 34,16 & 31,11 & 36,92 & 32,00 \\
\hline
\end{tabular}

Observações: fórmulas estruturais calculadas na base de 6 oxigênios; ferro analisado como $\mathrm{Fe}^{2+}$

* posição do ponto analisado em relação à proximidade do centro ou da borda do cristal.

Abreviações: a.p.f.u.: átomos por fórmula unitária; diop: diopsídio; aug: augita.

a $8,77 \%)$. O conteúdo médio de $\mathrm{CaO}$ é de $10,25 \%$, com $\mathrm{Na}_{2} \mathrm{O}$ entre $0,3 \%$ e $2,64 \%, \mathrm{~K}_{2} \mathrm{O}$ de $0,13 \%$ a $0,91 \%$ e $\mathrm{F}$ de $0,0 \%$ a $2,0 \%$ (Tab. 4). A fórmula estrutural dos anfibólios e a proporção $\mathrm{Fe}^{2+} / \mathrm{Fe}^{3+}$ foram calculadas com o programa MINPET 2.0, na base de 23 átomos de oxigênio. Para obtenção dos valores de $\mathrm{Fe}^{2+}$ e $\mathrm{Fe}^{3+}$ utilizou-se o sistema de normalização de Robinson et al. (1981). Segundo a nomenclatura de Leake et al. (1997), os anfibólios se enquadram no grupo dos anfibólios cálcicos, com composição de ferro-hornblenda, ferro-actinolita (Fig. 8) e localmente ferro-edenita.
A ferro-hornblenda é a composição dominante, com rara ferro-edenita. A ferro-actinolita restringese às bordas dos anfibólios (Fig. 9a). A composição da ferro-hornblenda é caracterizada por pequenas variações nos conteúdos de $\mathrm{SiO}_{2}, \mathrm{Al}_{2} \mathrm{O}_{3}, \mathrm{Na}_{2} \mathrm{O}, \mathrm{MgO}$ e $\mathrm{F}$. A transição para ferro-actinolita é marcada pelo aumento inicial no conteúdo de $\mathrm{Al}_{2} \mathrm{O}_{3}$, e diminuição brusca de $\mathrm{FeO}^{\mathrm{t}}$. Os conteúdos de $\mathrm{MgO}$ aumentam gradualmente em direção à borda de cristais de ferro-hornblenda. $\mathrm{Na}_{2} \mathrm{O}, \mathrm{K}_{2} \mathrm{O}, \mathrm{CaO}$ e $\mathrm{F}$ diminuem em direção à borda da ferro-hornblenda (Fig. 9b,c). 
a
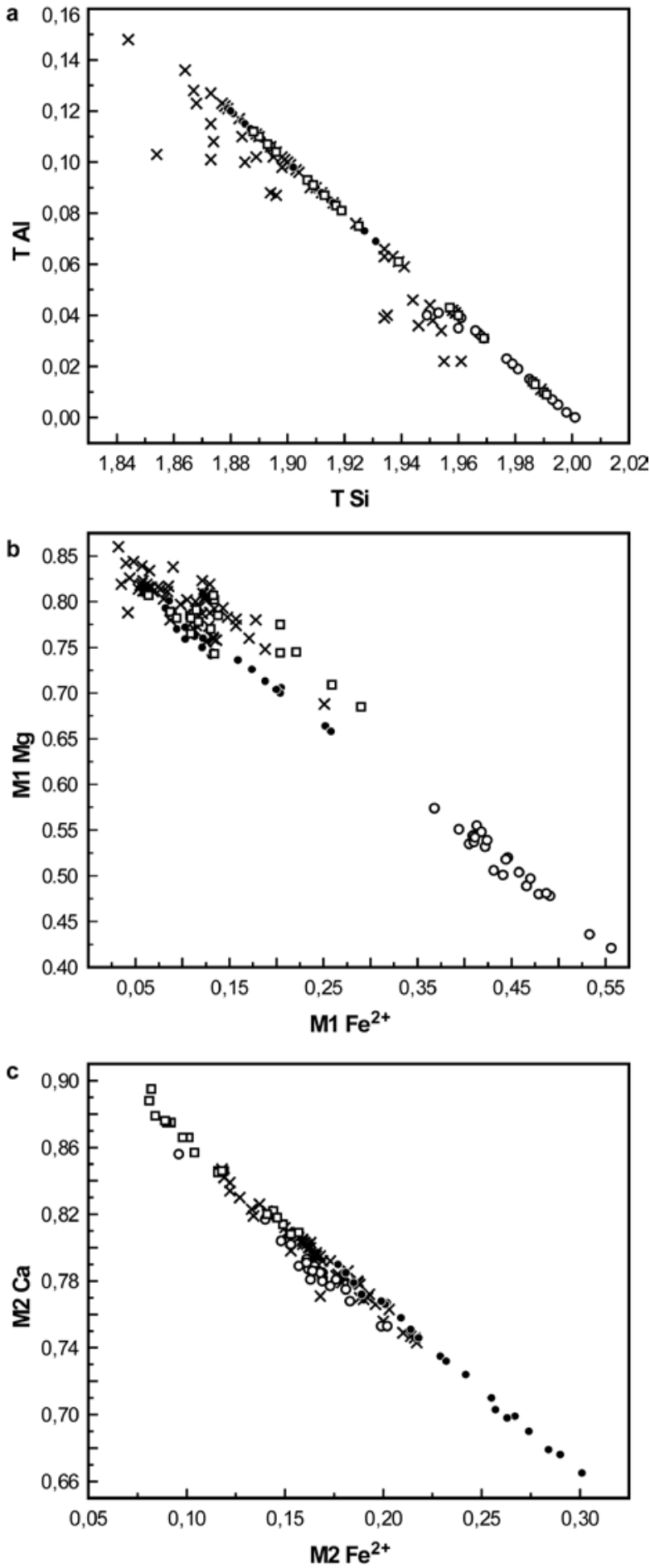

Figura 6 - Principais trocas catiônicas nos sitios T (a), M1 (b) e M2 (c), dos clinopiroxênios. Símbolos: idem a figura 5.

A ferro-actinolita possui composição heterogênea quando comparada à ferro-hornblenda. Essa variação é marcada pelo aumento gradual dos conteúdos de $\mathrm{SiO}_{2}$ até próximo da borda da ferro-actinolita, e sutil diminuição próximo a extremidade. $\mathrm{FeO}^{\mathrm{t}}$ e $\mathrm{MgO}$ possuem padrões inversos entre si, sendo que o $\mathrm{FeO}^{\mathrm{t}}$ tende a aumentar e o $\mathrm{MgO}$ tende a diminuir gradualmente em direção a extremidade. Os conteúdos de $\mathrm{CaO}$ indicam
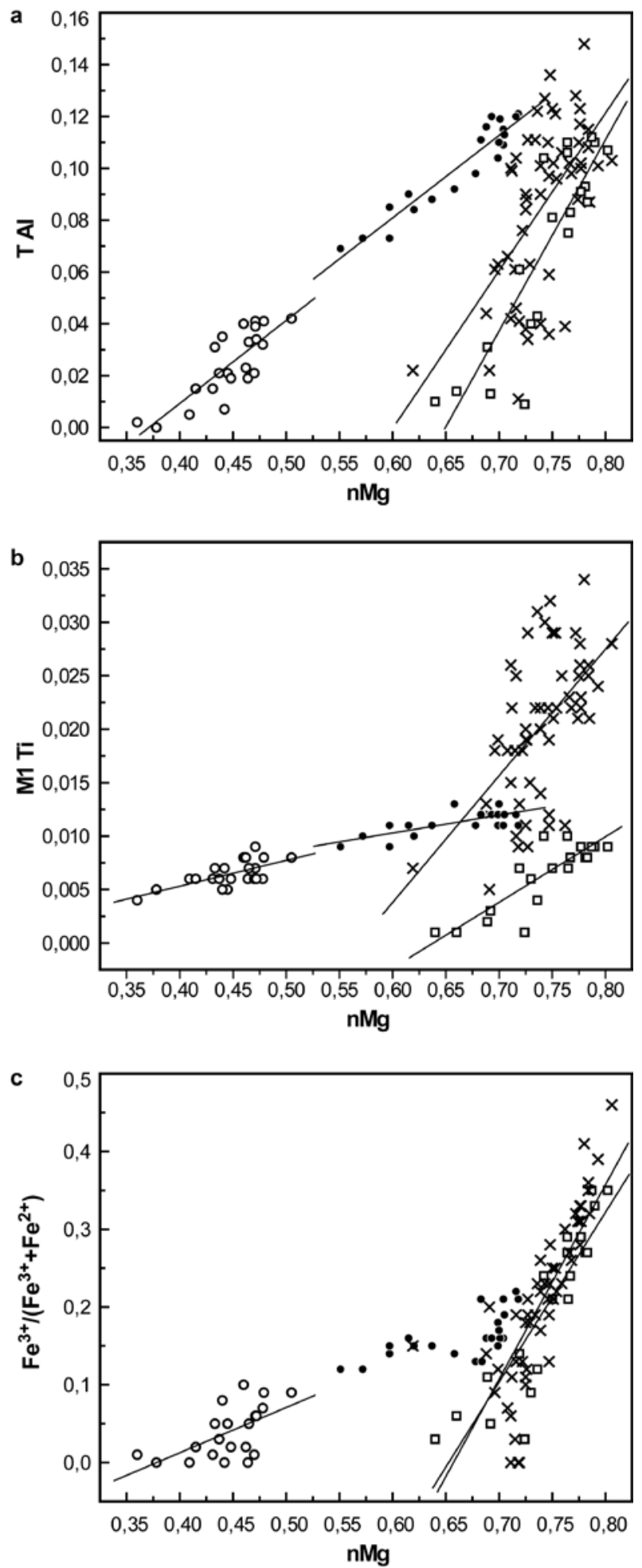

Figura 7 - Substituições catiônicas em relação a nMg em clinopiroxênios da Formação Quarenta Ilhas. Retas: regressões lineares que melhor se ajustam aos dados de cada grupo. a) ${ }^{T} \mathrm{Al}$ vs $\mathrm{nMg}$; b) ${ }^{\mathrm{T}} \mathrm{Ti}$ vs $\mathrm{nMg}$; c) $\mathrm{Fe}^{3+} /\left(\mathrm{Fe}^{3+}+\mathrm{Fe}^{2+}\right)$ vs $n M g$. Símbolos: idem a figura 5.

uma sutil variação, marcada por um aumento inicial e pequena diminuição em direção à extremidade. $\mathrm{Al}_{2} \mathrm{O}_{3}$, $\mathrm{Na}_{2} \mathrm{O}, \mathrm{K}_{2} \mathrm{O}$ e $\mathrm{F}$ tendem a diminuir em direção à borda, 
Tabela 4 - Análises representativas de anfibólios da Formação Quarenta Ilhas no Distrito Mineiro de Pitinga.

\begin{tabular}{|c|c|c|c|c|c|c|c|c|c|c|c|c|c|c|c|c|}
\hline Amostra & A24h & A24h & A24h & A24z & A24z & A24z & A24z & A24z & A24z & A24z & A24h & A24h & A24z & A24z & A24z & $\mathrm{A} 24 \mathrm{z}$ \\
\hline Análise & 20 & 21 & 25 & 06 & 09 & 15 & 18 & 22 & 23 & 25 & 26 & 27 & 17 & 24 & 35 & 36 \\
\hline Tipo & $\begin{array}{l}\text { Fe- } \\
\text { eden }\end{array}$ & $\begin{array}{l}\mathrm{Fe}- \\
\text { eden }\end{array}$ & Fe-hbl & Fe-hbl & Fe-hbl & Fe-hbl & Fe-hbl & Fe-hbl & Fe-hbl & Fe-hbl & Fe-actn & Fe-actn & $\mathrm{Fe}-\mathrm{actn}$ & Fe-actn & Fe-actn & $\mathrm{Fe}$-actn \\
\hline Posição* & centro & centro & centro & centro & centro & centro & entro & centro & centro & centro & oorda & borda & borda & borda & orda & orda \\
\hline \multicolumn{17}{|l|}{$\%$ em peso } \\
\hline $\mathrm{SiO}_{2}$ & 6,22 & 44,48 & 47,95 & 44,78 & 48,01 & 48,42 & 45,68 & 44,21 & 48,11 & 48,44 & 49,80 & 51,26 & 48,85 & 49,54 & 51,77 & 51,94 \\
\hline $\mathrm{TiO}_{2}$ &, 50 & 0,45 & 0,30 & 0,11 & 0,10 & 0,32 & 0,09 & 0,13 & 0,02 & 0,07 & 0,21 & 0,14 & 0,07 & 0,00 & 0,36 & 0,12 \\
\hline $\mathrm{Al}_{2} \mathrm{O}_{3}$ & 4,31 & 4,20 & 4,37 & 6,05 & 4,20 & 3,71 & 5,32 & 6,33 & 3,43 & 3,24 & 2,93 & 1,94 & 3,06 & 1,89 & 1,73 & 0,93 \\
\hline $\mathrm{FeO}$ & 26,85 & 25,89 & 24,15 & 26,70 & 25,64 & 23,51 & 28,07 & 29,08 & 27,68 & 27,75 & 24,93 & 25,17 & 26,99 & 28,91 & 22,97 & 26,80 \\
\hline & 48 & 0,52 & 0,55 & & 0,64 & & 1,02 & 0,91 & 1,53 & 1,03 & 0,52 & 0,76 & 1,01 & 2,18 & 0,96 & 1,81 \\
\hline $\mathrm{MgO}$ & 82 & 5,51 & 27 & 4,98 & 6,52 & 60 & 4,76 & 4,05 & 4,95 & 5,22 & 7,67 & 7,29 & 5,64 & 3,99 & 8,49 & 5,70 \\
\hline $\mathrm{CaO}$ & 9,65 & 9,90 & 10,48 & 11,16 & 11,39 & 9,88 & 11,03 & 11,05 & 11,03 & 11,02 & 10,74 & 11,01 & 10,98 & 10,86 & 11,04 & 11,16 \\
\hline & 40 & 2,13 & 72 & 1,20 & 0,92 & 71 & 1,11 & 1,27 & 0,72 & 0,70 & 1,18 & 0,78 & 0,71 & 0,46 & 0,68 & 0,30 \\
\hline $\mathrm{O}$ & 91 & 0,91 & 55 & 67 & 32 & 59 & 0,53 & 0,60 & 29 & 34 & 31 &, 21 & 0,28 & 0,22 & 0,29 & 13 \\
\hline $\mathrm{Cr}_{2} \mathrm{O}_{3}$ & 03 & 0,02 & 0,01 & 0,01 & 0,00 & 0,01 & 0,04 & 0,00 & 0,02 & 0,00 & 0,06 & 0,02 & 0,00 & 0,05 & 0,00 & 0,04 \\
\hline$\vec{F}$ & 1,64 & 0,89 & 0,99 & 0,06 & 0,20 & 84 & 0,10 & 0,03 & 0,00 & 0,00 & 38 & 0,00 & 0,08 & 0,00 & 0,35 & 0,00 \\
\hline $\mathrm{Cl}$ & 0,0 & & 00 & & & 00 & 0,00 & 0,01 & 0,01 & 0,01 & 0,00 & 0,00 & 0,00 & 0,02 & 0,01 & 0,01 \\
\hline Soma & 98,78 & 94,88 & 99,33 & 96,78 & 97,93 & 98,12 & 97,76 & 97,66 & 97,77 & 97,82 & 98,67 & 98,56 & 97,69 & 98,10 & 98,65 & 98,93 \\
\hline $\mathrm{O}=\mathrm{F}+\mathrm{Cl}$ & 0,69 & 0,37 & 0,42 & 0,03 & 0,09 & 0,35 & 0,04 & 0,01 & 0,00 & 0,00 & 0,16 & 0,00 & 0,03 & 0,00 & 0,15 & 0,00 \\
\hline Sum & 9,47 & 95,25 & 99,75 & 96,81 & 98,02 & & 97,80 & 97,67 & 97,77 & 97,82 & & 98,56 & 97,72 & 98,10 & 98,80 & 98,93 \\
\hline \multicolumn{17}{|l|}{ a.p.f.u. } \\
\hline \multicolumn{17}{|l|}{ Sítio T } \\
\hline Si & 219 & 220 & 7,221 & 043 & 7,366 & 7,323 & 7,114 & 6,934 & 445 & 482 & 7,512 & 7,728 & 530 & ,687 &, 757 & 7,888 \\
\hline $\mathrm{Al}^{1}$ & 781 & 80 & & & & & 0,886 & 066 & &, 518 & & 0,272 & 0,470 & 313 &, 243 & 0,112 \\
\hline $\mathrm{Ti}^{\mathrm{IV}}$ & 0,000 & 0,000 & 0,004 & 0,000 & 0,000 & 0,017 & 0,000 & 0,000 & 0,000 & 0,000 & 0,000 & 0,000 & 0,000 & 0,000 & 0,000 & 0,000 \\
\hline Soma sítio T & 8,000 & 8,000 & 8,000 & 8,000 & 8,000 & 8,001 & 8,000 & 8,000 & 8,000 & 8,000 & 8,000 & 8,000 & 8,000 & 8,000 & 8,000 & 8,000 \\
\hline \multicolumn{17}{|c|}{ Sítio C (M1, M2, M3) } \\
\hline $\mathrm{Al}^{\mathrm{VI}}$ & 0,012 & 0,023 & 0,000 & 0,164 & 0,124 & 0,000 & 0,089 & 0,103 & 0,070 & 0,071 & 0,033 & 0,073 & 0,085 & 0,033 & 0,063 & 0,054 \\
\hline $\mathrm{Cr}$ & 004 & 0,003 & 0,001 & 0,001 & 0,000 & 0,001 & 0,005 & 0,000 & 0,002 & 0,000 & 0,007 & 0,002 & 0,000 & 0,006 & 0,000 & 0,005 \\
\hline $\mathrm{Fe}^{3+}$ & 0,510 & 0,342 & 0,724 & & 0,406 & & 0,650 & 0,713 & 0,546 & 0,507 & 0,524 & 0,340 & 0,475 & 0,481 & 0,301 & 0,280 \\
\hline $\mathrm{Ti}^{\mathrm{VI}}$ & 0,059 & 0,055 & 0,030 & 0,013 & 0,012 & 0,019 & 0,011 & 0,015 & 0,002 & 0,008 & 0,024 & 0,016 & 0,008 & 0,000 & 0,041 & 0,014 \\
\hline $\mathrm{Mg}$ & 1,355 & 1,333 & 1,857 & 1,168 & 1,491 & 1,939 & 1,105 & 0,947 & 1,142 & 1,202 & 1,725 & 1,638 & 1,296 & 0,923 & 1,897 & 1,290 \\
\hline $\mathrm{Fe}^{2+}$ & 997 & 3,173 & 2,318 & 3,007 & 2,884 & & 3,006 & 3,101 & 3,036 & 3,077 & 2,621 & 2,834 & 3,004 & 3,271 & 2,577 & 3,124 \\
\hline $\mathrm{Mn}$ & 0,064 & 0,071 & 0,070 & 0,143 & 0,083 & 0,067 & 0,135 & 0,121 & 0,201 & 0,135 & 0,066 & 0,097 & 0,132 & 0,287 & 0,122 & 0,233 \\
\hline Soma s & 5,001 & 5,000 & 5,000 & 5,000 & 5,000 & 5,000 & 5,001 & 5,000 & 4,999 & 5,000 & 5,000 & 5,000 & 5,000 & 5,001 & 5,001 & 5,000 \\
\hline \multicolumn{17}{|l|}{ Sítio B (M4) } \\
\hline $\mathrm{Ca}$ & 1,615 & 1,722 & 1,691 & 1,881 & 1,872 & 1,601 & 1,840 & 1,857 & 1,829 & 1,824 & 1,736 & 1,778 & 1,813 & 1,806 & 1,772 & 1,816 \\
\hline $\mathrm{Na}$ & 0,385 & 0,278 & 0,309 & 0,119 & 0,128 & 0,399 & 0,160 & 0,143 & 0,171 & 0,176 & 0,264 & 0,222 & 0,187 & 0,138 & 0,198 & 0,088 \\
\hline Soma sí & 2,000 & 2,000 & 2,000 & 2,000 & 2,000 & 2,000 & 2,000 & 2,000 & 2,000 & 2,000 & 2,000 & 2,000 & 2,000 & 1,944 & 1,970 & 1,904 \\
\hline \multicolumn{17}{|l|}{ Sítio A } \\
\hline $\mathrm{Na}$ & 342 & 0,392 & 0,193 & 0,247 & 0,146 & 0,102 & 0,176 & 0,243 & 0,045 & 0,033 & 0,081 & 0,007 & 0,025 & 0,000 & 0,000 & 0,000 \\
\hline $\mathrm{K}$ & 0,181 & 0,188 & 0,106 & 0,134 & 0,063 & 0,114 & 0,105 & 0,120 & 0,057 & 0,067 & 0,060 & 0,040 & 0,055 & 0,044 & 0,055 & 0,025 \\
\hline & 0,523 & 0,581 & & & 0,418 & & 0,562 & 0,726 & & 0,200 & & 0,047 & 0,160 & 0,088 & 0,110 & 0,050 \\
\hline Soma cátions & 15,524 & 15,580 & 15,299 & 15,381 & 15,209 & 15,217 & 15,282 & 15,363 & 15,101 & 15,100 & 15,141 & $\mid 15,047$ & 15,080 & 14,989 & 15,026 & 14,929 \\
\hline
\end{tabular}

Observações: fórmulas estruturais calculadas na base de 23 oxigênios; ferro analisado como $\mathrm{Fe}^{2+}$

* posição do ponto analisado em relação à proximidade do centro ou da borda do cristal.

Abreviações: a.p.f.u.: átomos por fórmula unitária; F-eden: ferro-edenite; Fe-hbl: ferro-hornblenda; Fe-actn: ferro-actinolita.

possuindo conteúdos menos variáveis quando próximo a extremidade de cristais de ferro-actinolitas (Fig. 9b,c). Roberts et al. (2000) assumem que a cristalização de actinolita em gabros e rochas ultramáficas ocorre como resultado de reações com resíduos félsicos tardios, em um estágio subsolidus.

As variações composicionais indicam substituição simples do tipo $\mathrm{Si} \rightarrow \mathrm{Al}$ no sítio $\mathrm{T}, \mathrm{Mg} \rightarrow \mathrm{Fe}^{2+}$ no sítio $\mathrm{C}, \mathrm{Ca} \rightarrow \mathrm{Na}$ no sítio $\mathrm{B}$ e $\mathrm{Na} \rightarrow \mathrm{K}$ no sítio A. Trocas duplas como ${ }^{\mathrm{T}} \mathrm{Si}+{ }^{\mathrm{A}} \square \rightarrow{ }^{\mathrm{T}} \mathrm{Al}+{ }^{\mathrm{A}}(\mathrm{Na}+\mathrm{K})$, indicam atuação de substituição edenítica (Fig. 10) na evolução dos anfibólios da Formação Quarenta Ilhas.

ÓXIDOS DE FE-TI Os óxidos de Fe-Ti pertencem às séries de solução sólida ulvoespinélio-magnetita (magnetita $_{\mathrm{ss}}$ ) e ilmenita-hematita (ilmenita ${ }_{\mathrm{ss}}$ ). O conteúdo modal dos óxidos de Fe-Ti é de $\sim 10 \%$ em dioritos, e varia de $15 \%$ a $25 \%$ em diabásios e gabros. A magnetita consiste de grãos subédricos a anédricos, sendo mais abundante que a ilmenita. A ilmenita ocorre como cris- 


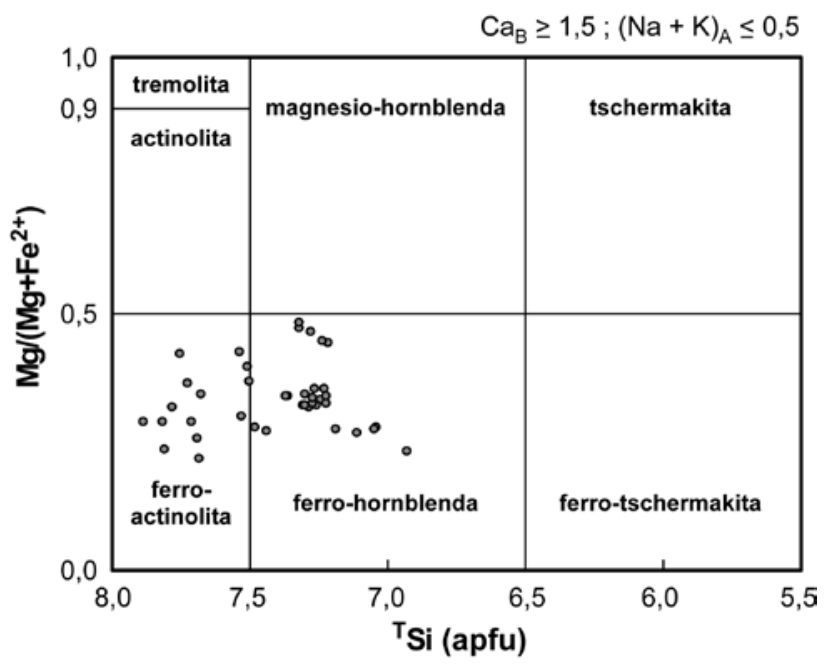

Figura 8 - Diagrama de classificação de anfibólios cálcicos de Leake et al. (1997).

tais subédricos inclusos em magnetita, segundo contatos retos sugerindo condições de equilíbrio (Fig. 11a). Grãos anédricos de ilmenita ocorrem ao longo das bordas da magnetita, o que pode estar indicando reações de oxidação subsolidus (Buddington \& Lindsley 1964). A ilmenita também ocorre como finas lamelas de exsolução/oxidação em magnetita. Grãos isolados de ilmenita ocorrem localmente (Fig. 11b).

Feições típicas de desequilíbrio nos óxidos de Fe-Ti consistem de textura em peneira em magnetita e textura treliça. A textura treliça ocorre de forma localizada em alguns grãos de magnetita, caracterizada por lamelas delgadas de ilmenita distribuídas ao longo de dois dos planos $\{111\}$ da magnetita (Fig. 11c). Nas rochas intermediárias, alguns grãos de magnetita possuem lamelas relativamente mais espessas $(<15 \mu \mathrm{m})$ de ilmenita ao longo dos planos $\{111\}$ da magnetita (Fig. 11d). Essas feições indicam que o resfriamento relativamente lento das rochas intermediárias, aliado a mais alta $\mathrm{fO}_{2}$, deve ter favorecido reações de oxidação/exsolução de ilmenita em magnetita (Buddington \& Lindsley 1964). A titanita está frequentemente associada à magnetita $\mathrm{e}$ ilmenita, o que sugere oxidação em estágios subsolidus (Carmichael \& Nicholls 1967).

A ocorrência de grãos isolados de ilmenita, seguidos de magnetita com textura treliça (em estágios iniciais e avançados), e grânulos de ilmenita nas bordas de magnetita, indica aumento sistemático do grau de oxidação e difusão de óxidos de Fe-Ti (Buddington \& Lindsley 1964). Frost \& Lindsley (1992) atribuem esse processo a fenômenos de oxi-exsolução.

As fórmulas estruturais de magnetita e ilmenita foram recalculadas na base de 4 e 3 oxigênios, respectivamente (Tab. 5). Os conteúdos de $\mathrm{FeO}$ e $\mathrm{Fe}_{2} \mathrm{O}_{3}$ e as proporções moleculares (Usp-Mt e Ilm-Hem) foram recalculados segundo os procedimentos de Carmichael (1967). O gráfico da figura 12 ilustra a proporção entre $\mathrm{TiO}_{2}, \mathrm{FeO}$ e $\mathrm{Fe}_{2} \mathrm{O}_{3}$ segundo as séries de solução
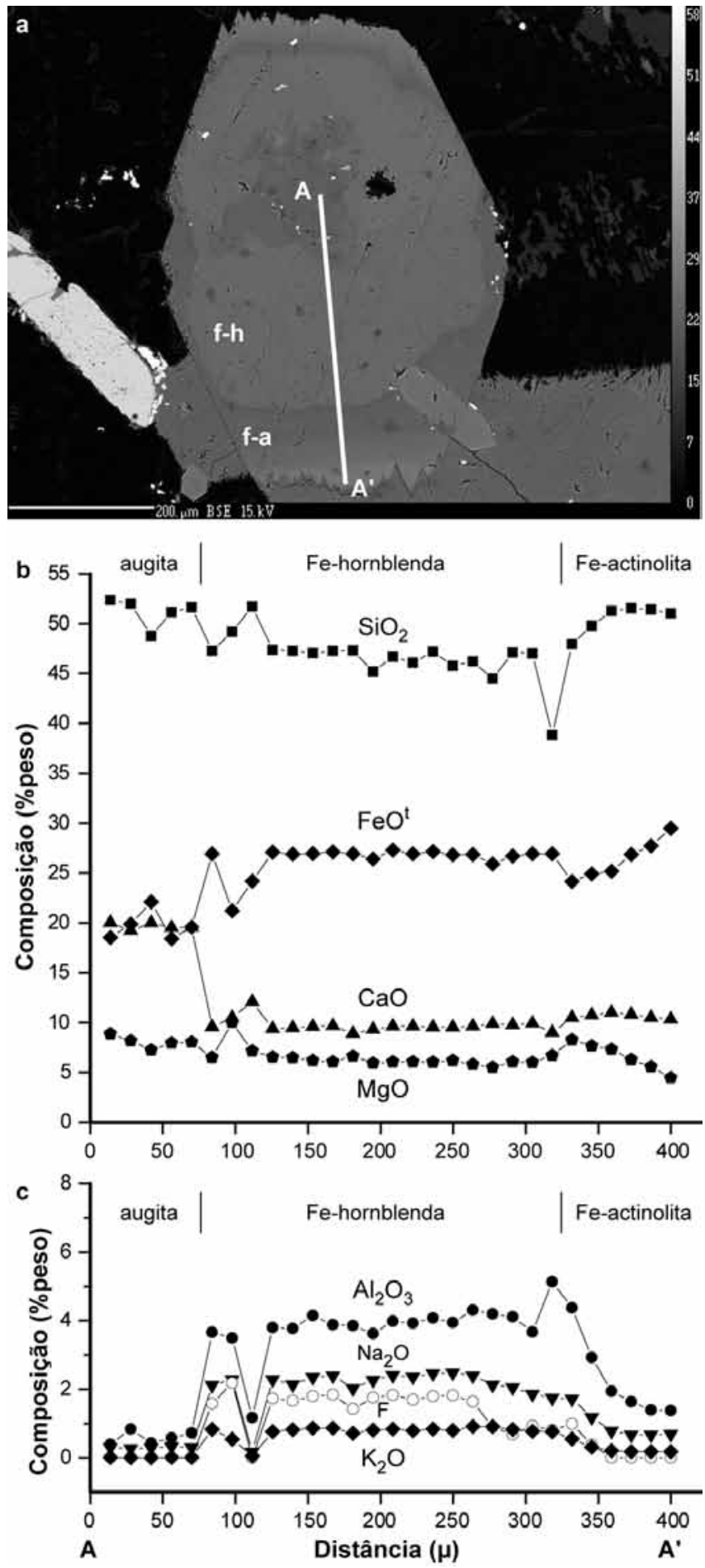

Figura 9 - Variação composicional em piroxênio e anfibólio de textura ofitica em diorito da Formação Quarenta Ilhas. a) Imagem EDS com localização do perfil composicional do núcleo do piroxênio (A) para a borda do anfibólio (A'); b) Variação de $\mathrm{SiO}_{2}, \mathrm{FeO}, \mathrm{CaO} e$ $\mathrm{MgO}$; c) Variação de $\mathrm{Al}_{2} \mathrm{O}_{3}, \mathrm{Na}_{2} \mathrm{O}, \mathrm{F}$ e $\mathrm{K}_{2} \mathrm{O}$. Abreviaçôes: $f$-h: ferro-hornblenda; f-a: ferro-actinolita.

sólida Usp-Mt e Ilm-Mt. A composição da magnetita varia de Usp ${ }_{22}$ a Usp ${ }_{37}$ e é caracterizada por moderados conteúdos de $\mathrm{TiO}_{2}$ (de 7,36\% a 14,69\%), alto $\mathrm{Fe}_{2} \mathrm{O}_{3}$ (de 


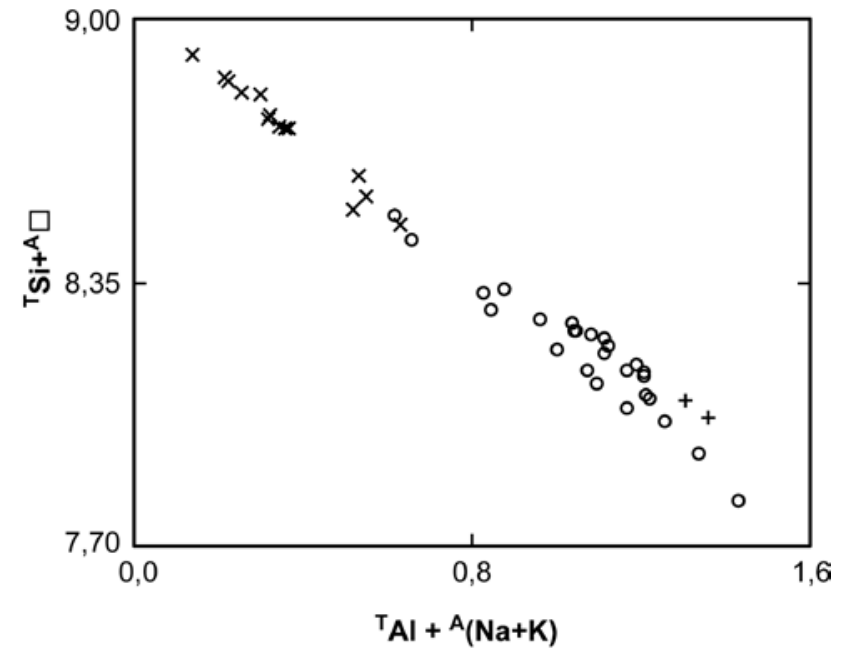

Figura 10 - Substituição edenítica nos anfibólios da Formação Quarenta Ilhas. Símbolos: o - ferro-hornblenda; $x$-ferro-actinolita; + -ferro-edenita.

$35,47 \%$ a $50,07 \%$ ) e $\mathrm{FeO}$ entre $36,82 \%$ e $43,54 \%$. Os conteúdos de $\mathrm{Al}_{2} \mathrm{O}_{3}$ variam de $0,35 \%$ a $1,95 \%, \mathrm{MnO}$ de $0,18 \%$ a $0,87 \%$ e V${ }_{2} \mathrm{O}_{3}$ entre $0,82 \%$ a $1,21 \%$. A ilmenita possui composiçã̃o no intervalo $\operatorname{Ilm}_{87-95}$ com conteúdos de $\mathrm{TiO}_{2}$ entre $46,35 \%$ e $49,34 \%$, $\mathrm{FeO}$ de $38,82 \%$ a $42,47 \%$ e $\mathrm{Fe}_{2} \mathrm{O}_{3}$ entre $3,16 \%$ e $11,33 \%$. $\mathrm{V}_{2} \mathrm{O}_{3}$ varia de
$1,66 \%$ a $2,04 \%$ e o $\mathrm{MnO}$ de $1,79 \%$ a $3,59 \%$.

Temperaturas de equilíbrio entre os pares de ilmenita e magnetita, segundo o geotermômetro de Carmichael (1967), indicam valores entre $868^{\circ} \mathrm{C}$ e $703^{\circ} \mathrm{C}$. Bellieni et al. (1986) obteve temperaturas entre $600^{\circ} \mathrm{C}$ e $1100^{\circ} \mathrm{C}$ para óxidos de $\mathrm{Fe}-\mathrm{Ti}$ de rochas hipabissais toleíticas da Formação Serra Geral. Esses autores assumem que as temperaturas inferiores a $1000^{\circ} \mathrm{C}$ representam um estágio de reequilíbrio e resfriamento pósintrusivo.

Ordem de Cristalização A ordem de cristalização dos minerais das rochas básicas a intermediárias e sua evolução por cristalização fracionada foi estabelecida de acordo com dados petrográficos e de química mineral (Fig. 13). Nos diabásios e gabros a cristalização inicia-se com olivina, seguida de augita+plagioclásio, ilmenita e posteriormente titanomagnetita. O plagioclásio, tanto nas rochas básicas quanto nas intermediárias, possui núcleo labradorítico evoluindo até oligoclásio nas bordas dos cristais. A cristalização de ferro-hornblenda inicia-se no magma diorítico, formando textura coronítica em augita e indicando aumento da atividade de voláteis com a diferenciação. $\mathrm{O}$ resíduo de cristalização é constituído por feldspato alcalino e quartzo formando intercrescimentos micrográficos, possivelmente acompanhado da cristalização de oligoclásio. A cristalização de ferro-actinolita, desenvolvimento das pertitas
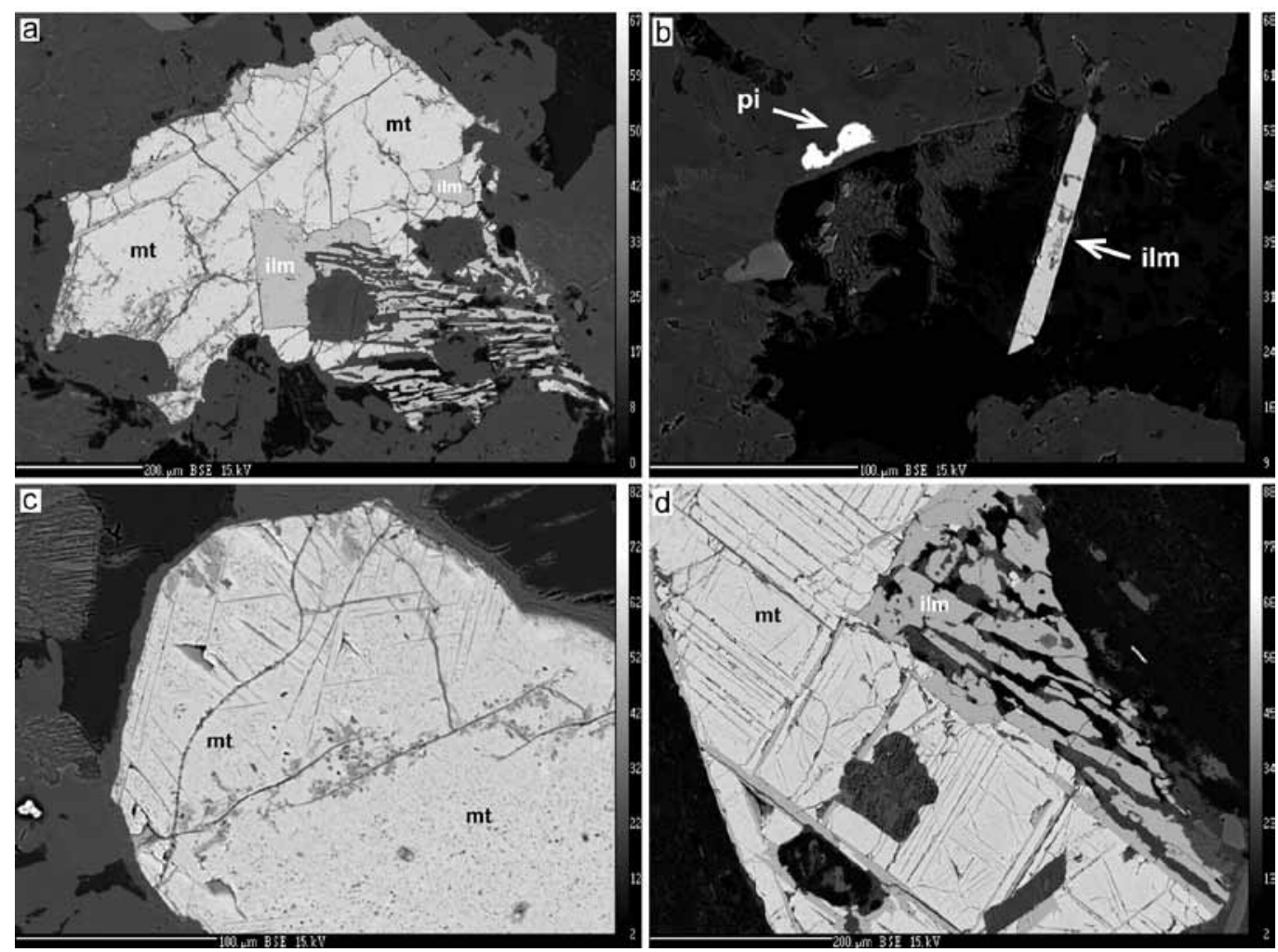

Figura 11 - Feições petrográficas dos óxidos de Fe-Ti. a) ilmenita inclusa em magnetita; b) ilmenita euédrica; c) magnetita com textura em peneira e textura treliça; d) lamelas de ilmenita ao longo dos planos \{111\} da magnetita. Abreviações: mt-magnetita, ilm-ilmenita, pi-pirita. 
Tabela 5 - Análises representativas de óxidos de Fe-Ti da Formação Quarenta Ilhas no Distrito Mineiro de Pitinga.

\begin{tabular}{|c|c|c|c|c|c|c|c|c|c|c|c|c|c|c|c|c|}
\hline Amostra & A24a & $\mathrm{A} 24 \mathrm{a}$ & A24a & A24a & A88a & A88a & A88a & A88a & A88a & A88a & $\mathrm{A} 89 \mathrm{~b}$ & $\mathrm{~A} 89 \mathrm{~b}$ & $\mathrm{~A} 89 \mathrm{~b}$ & $\mathrm{~A} 89 \mathrm{~b}$ & A89b & $\mathrm{A} 89 \mathrm{~b}$ \\
\hline Análise & 06 & 11 & 07 & 12 & 22 & 32 & 14 & 16 & 12 & 11 & 05 & 04 & 03 & 01 & 16 & 11 \\
\hline Tipo & ilm & $\mathrm{mt}$ & ilm & $\mathrm{mt}$ & ilm & $\mathrm{mt}$ & ilm & $\mathrm{mt}$ & ilm & $\mathrm{mt}$ & ilm & $\mathrm{mt}$ & ilm & $\mathrm{mt}$ & ilm & $\mathrm{mt}$ \\
\hline Posição* & centro & centro & centro & centro & centro & centro & borda & centro & borda & centro & centro & centro & borda & centro & borda & centro \\
\hline \multicolumn{17}{|l|}{$\%$ em peso } \\
\hline $\mathrm{SiO}_{2}$ & 0,11 & 0,52 & 0,09 & 0,72 & 0,45 & 0,14 & 0,03 & 0,09 & 0,06 & 0,52 & 0,05 & 0,13 & 0,07 & 0,07 & 0,05 & 0,08 \\
\hline $\mathrm{TiO}_{2}$ & 47,87 & 7,43 & 48,06 & 9,39 & 47,85 & 8,08 & 46,78 & 9,60 & 46,35 & 7,43 & 48,39 & 10,59 & 47,57 & 9,63 & 47,49 & 11,46 \\
\hline $\mathrm{Al}_{2} \mathrm{O}_{3}$ & 0,00 & 1,50 & 0,00 & 1,56 & 0,00 & 2,98 & 0,00 & 1,56 & 0,00 & 1,50 & 0,00 & 1,68 & 0,00 & 1,20 & 0,00 & 2,49 \\
\hline $\mathrm{Fe}_{2} \mathrm{O}_{3}$ & 6,20 & 49,46 & 5,53 & 45,00 & 6,41 & 47,87 & 9,30 & 46,06 & 9,21 & 49,46 & 7,38 & 44,71 & 8,32 & 47,51 & 8,91 & 41,90 \\
\hline $\mathrm{FeO}$ & 39,88 & 36,82 & 39,84 & 39,09 & 40,54 & 38,36 & 40,03 & 39,04 & 39,28 & 36,82 & 41,23 & 40,60 & 40,77 & 39,44 & 40,70 & 41,05 \\
\hline $\mathrm{MnO}$ & 3,21 & 0,62 & & 0,59 & 2,43 & 0,35 & 1,96 & 0,64 & 2,27 & 0,62 & 2,12 & 0,50 & 1,90 & 0,58 & 1,95 & 0,64 \\
\hline $\mathrm{MgO}$ & 0,00 & 0,14 & & 0,26 & 0,03 & 01 & 0,03 & 0,00 & 01 & 0,14 & 0,02 & 02 & 0,02 & 0,01 & 0,02 & 0,02 \\
\hline $\mathrm{CaO}$ & 05 & 0,08 & 4 & 0,04 & 0,40 & 97 & 0,01 & 0,06 & 04 & 0,08 & 0,04 & 0,03 & 0,05 & 0,01 & 0,04 & 0,07 \\
\hline $\mathrm{Cr}_{2} \mathrm{O}_{3}$ & 01 & 0,03 & 0,01 & 01 & 0,00 & 02 & 0,00 & 0,03 & 00 & 0,03 & 0,00 &, 04 & 0,04 & 0,02 & 0,00 & 0,02 \\
\hline $\mathrm{ZnO}$ & 0,00 & 0,77 & 0,00 & 0,32 & 0,03 & 0,10 & 0,03 & 0,05 & 0,12 & 0,77 & 0,15 & 0,00 & 0,08 & 0,18 & 0,01 & 0,08 \\
\hline $\mathrm{V}_{2} \mathrm{O}_{3}$ & 1,87 & 1,10 & 1,95 & 1,08 & 1,74 & 0,87 & 1,80 & 1,00 & 1,77 & 1,10 & 1,86 & 0,98 & 2,02 & 1,02 & 1,92 & 1,01 \\
\hline $\mathrm{NiO}$ & & 0,00 & & 0,00 & & & & & & 0,00 & 0,00 & & & 0,03 & & 0,01 \\
\hline Soma & 99,21 & 98,47 & 98,93 & 98,07 & 99,94 & 98,85 & 99,98 & 98,14 & 99,12 & 98,47 & \begin{tabular}{|l|}
101,24 \\
\end{tabular} & 99,28 & 100,85 & 99,71 & 101,08 & 98,84 \\
\hline \multicolumn{17}{|l|}{ a.p.f.u. } \\
\hline $\mathrm{Si}$ & 03 & 020 & 002 & 028 & 011 & 005 & 0,001 & 0,004 & ,001 & 0,020 & 0,001 &, 005 & 0,002 & 0,003 & 0,001 & 0,003 \\
\hline $\mathrm{Ti}$ & 919 & 0,215 & 0,924 & 0,271 & 0,910 & 231 & 0,892 & 0,278 & 0,892 & 0,215 & 0,911 & 0,303 & 0,899 & 0,275 & 0,895 & 0,327 \\
\hline $\mathrm{Al}$ & 0,000 & 0,068 & 0,000 & 0,071 & 0,000 & 0,134 & 0,000 & 0,071 & 0,000 & 0,068 & 0,000 & 0,075 & 0,000 & 0,054 & 0,000 & 0,111 \\
\hline $\mathrm{Fe}^{3+}$ & 0,119 & 1,428 & & 1,299 & 0,122 & 1,368 & 0,177 & 1,334 & 0,177 & 1,428 & 0,139 & 1,278 & 0,157 & 1,358 & 0,168 & 1,197 \\
\hline $\mathrm{Fe}^{2+}$ & & 1,182 & & 1,254 & & & 0,849 & 1,257 & 0,840 & 1,182 & 0,862 & 1,290 & 0,856 & 1,253 & 0,853 & 1,303 \\
\hline $\mathrm{Mn}$ & 0,069 & 0,020 & 0,074 & 0,019 & 0,052 & 0,011 & 0,042 & 0,021 & 0,049 & 0,020 & 0,045 & 0,016 & 0,040 & 0,019 & 0,041 & 0,021 \\
\hline $\mathrm{Mg}$ & 0,000 & 0,008 & 0,000 & 0,015 & 0,001 & 0,001 & 0,001 & 0,000 & 0,000 & 0,008 & 0,001 & 0,001 & 0,001 & 0,001 & 0,001 & 0,001 \\
\hline $\mathrm{Ca}$ & & & & & & & & 0,002 & & & 0,001 & & & & & 0,003 \\
\hline $\mathrm{Cr}$ & 0,000 & 0,001 & 0,000 & 0,000 & 0,000 & 0,001 & 0,000 & 0,001 & 0,000 & 0,001 & 0,000 & 0,001 & 0,001 & 0,001 & 0,000 & 0,001 \\
\hline $\mathrm{Zn}$ & 0,000 & 0,022 & 0,000 & 0,009 & 0,001 & 0,003 & 0,001 & 0,002 & 0,002 & 0,022 & 0,003 & 0,000 & 0,002 & 0,005 & 0,000 & 0,002 \\
\hline $\mathrm{V}$ & 038 & 0,034 & & & & & & & & & 0,037 & & & & 0,039 & 0,031 \\
\hline $\mathrm{Ni}$ & 0,000 & 0,000 & 0,000 & 0,000 & 0,001 & 0,000 & 0,000 & 0,000 & 0,000 & 0,000 & 0,000 & 0,000 & 0,000 & 0,001 & 0,000 & 0,000 \\
\hline $\begin{array}{l}\text { Soma } \\
\text { cátions }\end{array}$ & 2,000 & 3,000 & 2,000 & 3,000 & 2,000 & 3,000 & 2,000 & 3,000 & 2,000 & 3,000 & 2,000 & 3,000 & 2,000 & 3,000 & 2,000 & 3,000 \\
\hline $\operatorname{Ilm}(\mathrm{Mol} \%)$ & 92,12 & & 92,68 & & 92,10 & & 89,30 & & 89,32 & & 91,18 & & 90,06 & & 89,66 & \\
\hline Usp (Mol\%) & & 23,45 & & 29,86 & & 23,60 & & 28,15 & & 23,45 & & 30,78 & & 27,79 & & 33,03 \\
\hline Temp. $\left({ }^{\circ} \mathrm{C}\right)$ & 737 & & 748 & & 738 & & 797 & & 815 & & 777 & & 783 & & 810 & \\
\hline
\end{tabular}

Observações: fórmulas estruturais calculadas na base de 3 oxigênios para ilmenita e na base de 4 oxigênios para magnetita.

* posição do ponto analisado em relação à proximidade do centro ou da borda do cristal.

Abreviações: a.p.f.u.: átomos por fórmula unitária; ilm: ilmenita; mt: magnetita; Ilm: ilmenita; Usp: ulvoespinélio.

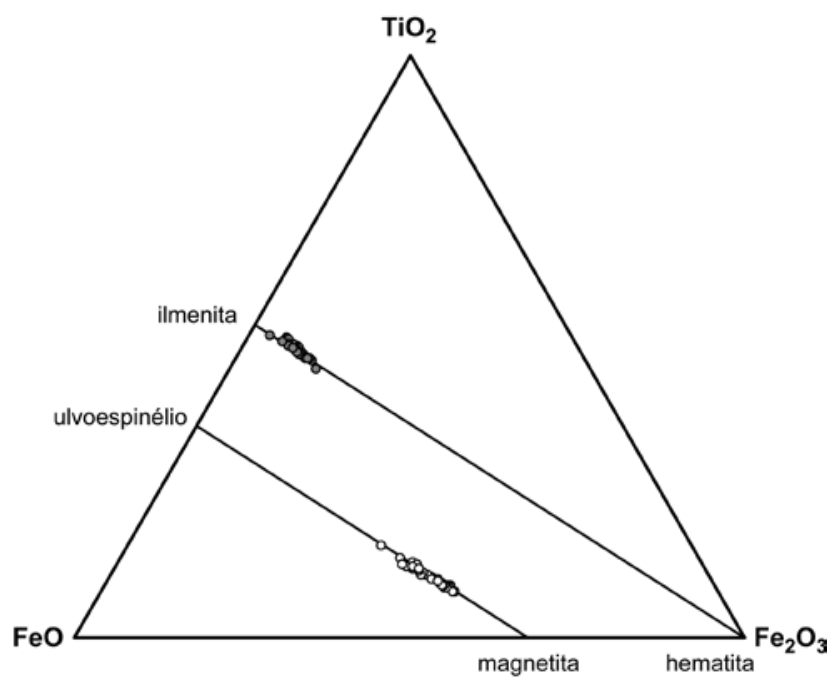

Figura 12 - Variações composicionais de ilmenita e magnetita coexistentes nas rochas básicas e intermediárias da Formação Quarenta Ilhas.

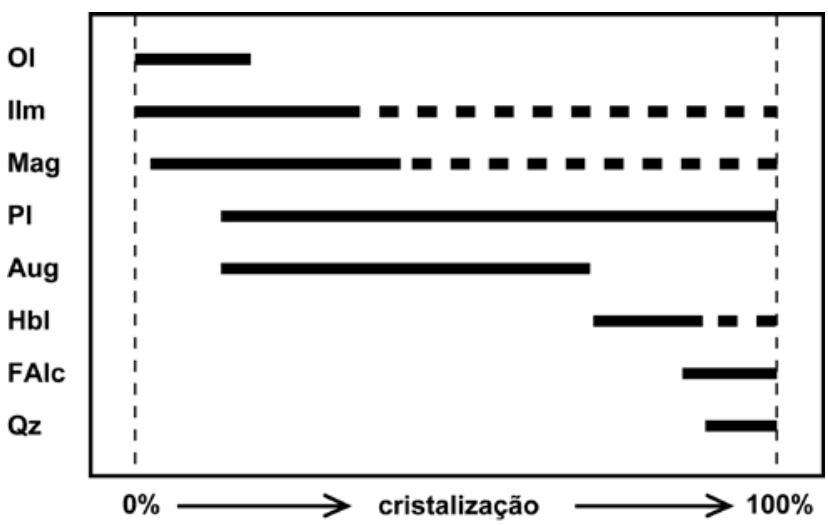

Figura 13 - Ordem de cristalização de gabro a quartzo diorito da Formação Quarenta Ilhas. Abreviações: Ololivina; Ilm-ilmenita; Mag-magnetita; Pl-plagioclásio; Aug-augita; Hbl-hornblenda; FAlc-feldspato alcalino; Qz-quartzo. 
e as feições de reequilíbrio na titanomagnetita, estão relacionadas ao estágio subsolvus. A substituição pseudomórfica de olivina por ferro-saponita, a geração de micas brancas e a cristalização de carbonatos e sulfetos, são provenientes da percolação de fluidos hidrotermais.

GEOQUÍMICA As rochas básicas e intermediárias da Formação Quarenta Ilhas possuem conteúdos de $\mathrm{SiO}_{2}$, recalculados para base anidra, de $44,49 \%$ a $54,99 \%$. Caracterizam-se por altos teores de $\mathrm{TiO}_{2}$ $(>2,0 \%)$, alto $\mathrm{Fe}_{2} \mathrm{O}_{3}{ }^{\mathrm{t}}(13,29 \%-20,23 \%), \mathrm{MgO}$ entre $1,98 \%$ e $6,81 \%, \mathrm{~K}_{2} \mathrm{O}$ de 0,54 a $2,34 \%, \mathrm{CaO}$ entre $5,29 \%$ e $11,17 \%$, e $\mathrm{P}_{2} \mathrm{O}_{5}$ entre $0,24 \%$ e $0,99 \%$ (Tab. 6). O conteúdo relativo de elementos traço, principalmente de $\mathrm{Nb}$, permite individualizar dois grupos químicos de diabásios: alto- $\mathrm{Nb}$ e baixo-Nb. O conteúdo de $\mathrm{Nb}$ varia de 2,4 ppm a 5,3 ppm no grupo baixo-Nb, enquanto os diabásios alto- $\mathrm{Nb}$ possuem $\mathrm{Nb}$ entre 12,9 ppm e 13,5 ppm. Nos termos mais diferenciados, dioríticos e quartzo dioríticos, os conteúdos de $\mathrm{Nb}$ concentram-se entre $8,8 \mathrm{ppm}$ e $11,6 \mathrm{ppm}$. Os diabásios baixo- $\mathrm{Nb}$ possuem baixo Hf, $\mathrm{Rb}, \mathrm{Ta}, \mathrm{Th}, \mathrm{U}, \mathrm{Cu}$ e $\mathrm{Zr}$, e elevado $\mathrm{Sr}$ e $\mathrm{MnO}$ (amostras A87b, A88a, A89a, A90a e A91a). Os elevados conteúdos de $\mathrm{Nb}, \mathrm{Hf}, \mathrm{Rb}, \mathrm{Ta}, \mathrm{Th}, \mathrm{U}$ e $\mathrm{Zr}$ dos diabásios alto-Nb (amostras A94a e A96a) se aproximam daqueles observados nos dioritos e quartzo dioritos. A amostra de gabro (A24a) é quimicamente compatível aos diabásios baixo-Nb. As amostras de diorito e quartzo diorito (A24f, A24e, A24h e A24z) possuem padrão composicional semelhante ao de diabásios baixo-Nb, entretanto com teores relativamente mais elevados.

As variações composicionais são melhores expressas utilizando-se $\mathrm{MgO}$ como índice de diferenciação. $\mathrm{O} \mathrm{MgO}$ diminui com a diferenciação e apresenta correlação negativa com $\mathrm{CaO}, \mathrm{Fe}_{2} \mathrm{O}_{3}{ }^{\mathrm{t}}$, $\mathrm{V} \mathrm{e} \mathrm{Co}$, sugerindo fracionamento de augita e óxidos de Fe-Ti (Fig. 14). A correlação positiva entre o índice de diferenciação e o $\mathrm{P}_{2} \mathrm{O}_{5}$, aliada a dados petrográficos, sugere acumulação de apatita. As variações de Th, Nb, Zr, Y e ETR em relação ao índice atestam o comportamento incompatível desses elementos durante a cristalização. Os baixos conteúdos de $\mathrm{Cr}$ e $\mathrm{Ni}$ podem indicar fracionamento de olivina e piroxênio.

No diagrama TAS (Fig. 15a) as rochas ocupam preferencialmente o campo do basalto, com uma amostra no campo do picrobasalto e uma no campo do traquibasalto. As amostras mais diferenciadas ocupam o campo do traquiandesito basáltico. Segundo a sistemática de Winchester \& Floyd (1977), as rochas básicas são classificadas como basaltos de afinidade subalcalina. Os termos mais diferenciados consistem de andesitos basálticos e andesitos (Fig. 15b).

Os elementos maiores e traços, normalizados segundo o padrão de manto primitivo, indicam diminuição nos conteúdos dos elementos de maior incompatibilidade quando utilizado o padrão de normalização do manto primitivo de Sun \& McDonough (1989) (Fig. $16 \mathrm{a}, \mathrm{b})$. Anomalias negativas de $\mathrm{Rb}, \mathrm{Nb}$ e $\mathrm{Zr}$ podem ser observadas nas amostras de diabásio baixo-Nb, gabro e dioritos. Essas feições podem estar associadas a ca- racterísticas da fonte magmática. Em algumas amostras de diabásio baixo-Nb (A91a, A87b e A89a), as anomalias positivas de $\mathrm{Sr}$ e Eu (Fig. 16a,c) sugerem acumulação de plagioclásio. Nas amostras de diabásio alto- $\mathrm{Nb}$ (A94a e A96a) não são observadas anomalias negativas de $\mathrm{Rb}$ e $\mathrm{Zr}$, enquanto a anomalia de $\mathrm{Nb}$ é menos acentuada. Observam-se, no entanto, anomalias negativas de $\mathrm{Sr}$ e Ti, as quais não estão presentes em diabásios baixo-Nb. A anomalia de Ti pode estar associada ao fracionamento de óxidos de $\mathrm{Fe}-\mathrm{Ti}$. O baixo conteúdo de $\mathrm{Sr}$ em diabásios alto- $\mathrm{Nb}$, aliado a anomalia de $\mathrm{Eu}$, devem ter sido ocasionado pela alteração de plagioclásio, conforme corroborado por dados petrográficos. Nas rochas intermediárias, as anomalias negativas de $\mathrm{Sr}$ e Ti sugerem fracionamento de óxidos de Fe-Ti e plagioclásio (Fig. 16b). A ausência de anomalia negativa de Eu nos dioritos, quando observada em diagrama de ETR normalizado pelo padrão condrítico de Boynton (1984) (Fig. 16c), pode estar relacionada ao fracionamento de augita concomitante ao de plagioclásio. $\mathrm{O}$ fracionamento de augita compensaria o empobrecimento em $\mathrm{Sr}$ gerado pelo fracionamento de plagioclásio.

A afinidade geoquímica toleítica das rochas da Formação Quarenta Ilhas pode ser ilustrada no diagrama AFM (Fig. 17). A razão Y/Nb nas rochas básicas baixo- $\mathrm{Nb}$ varia de 8,49 a 13,42, enquanto nos diabásios alto- $\mathrm{Nb}$, essa razão é de aproximadamente 4,0 . Segundo Pearce \& Cann (1973), razões Y/Nb maiores que a unidade indicam afinidade com magmas toleíticos. $\mathrm{O}$ caráter toleítico também é sugerido pelo conteúdo de minerais normativos: segundo o sistema haplobasáltico de Yoder \& Tilley (1962), as rochas básicas podem ser classificadas como toleítos supersaturados (quartzo+hiperstênio normativos) e como olivina toleítos (olivina+hiperstênio normativos). Além disso, no diagrama de Miyashiro (1974), as rochas básicas apresentam um trend paralelo àquele observado em magmas toleíticos (Fig. 18). A razão $(\mathrm{La} / \mathrm{Yb})_{\mathrm{N}}$ com valores próximos a 3 é similar a de toleítos havaianos. A razão $\mathrm{Zr} / \mathrm{Nb}$ em torno de 29,5 para a associação baixo-Nb, e de aproximadamente 17,0 para diabásios alto- $\mathrm{Nb}$, além da razão $\mathrm{Th} / \mathrm{La}$ próxima a 0,1 , sugerem afinidade com magmas do tipo MORB.

As razões Ti/V variam de 23 a 41 e são compatíveis com aquelas sugeridas por Shervais (1982) para basaltos de províncias continentais ou de cordilheira mesoceânica. As razões $\mathrm{La} / \mathrm{Nb}$ indicam valores médios de 4,7 para a associação baixo- $\mathrm{Nb}$ e em torno de 2,2 para diabásios alto-Nb. Fitton et al. (1988) e Leat et al. (1988) sugerem que magmas com altas razões $\mathrm{La} / \mathrm{Nb}(>1,5)$ podem estar relacionados a fontes de manto litosférico subcontinental. Thompson \& Morrinson (1988) sugerem que basaltos toleíticos com baixos conteúdos de $\mathrm{Nb}$ em relação à ETRL podem estar relacionados a fontes de manto litosférico modificado por subducção.

Os conteúdos de elementos maiores e traços das rochas básicas da Formação Quarenta Ilhas, quando comparados ao padrão E-MORB (Fig. 19), são marcados pelo enriquecimento em $\mathrm{Cs}, \mathrm{Rb}, \mathrm{Ba}$ e $\mathrm{K}$, e empobrecimento em Nb e Zr, Best (1975) e Saunders 
Tabela 6 - Dados litoquímicos das rochas básicas e intermediárias da Formação Quarenta Ilhas no Distrito Mineiro de Pitinga.

\begin{tabular}{|c|c|c|c|c|c|c|c|c|c|c|c|c|}
\hline Amostra & A91a & A89c & $\mathrm{A} 87 \mathrm{~b}$ & A90a & A88a & A24a & A94a & A96a & A24f & A24e & A24h & $\mathrm{A} 24 \mathrm{z}$ \\
\hline Litotipo & $\mathrm{Db}$ & $\mathrm{Db}$ & $\mathrm{Db}$ & $\mathrm{Db}$ & $\mathrm{Db}$ & $\mathrm{Gb}$ & $\mathrm{Db}$ & $\mathrm{Db}$ & $\mathrm{Dr}$ & $\mathrm{Dr}$ & $\mathrm{Dr}$ & Dr \\
\hline $\mathrm{SiO}_{2}$ & 45,20 & 44,49 & 46,54 & 47,56 & 47,24 & 47,74 & 49,68 & 49,84 & 50,98 & 51,73 & 54,90 & 54,99 \\
\hline $\mathrm{TiO}_{2}^{2}$ & 2,23 & 2,74 & 2,13 & 2,91 & 2,51 & 2,62 & 2,38 & 2,39 & 2,97 & 2,65 & 2,12 & 2,11 \\
\hline $\mathrm{Al}_{2} \mathrm{O}_{3}$ & 15,52 & 11,54 & 15,96 & 12,24 & 12,16 & 13,30 & 13,52 & 13,88 & 12,60 & 12,85 & 13,43 & 12,94 \\
\hline $\mathrm{Fe}_{2} \mathrm{O}_{3}{ }^{\mathrm{t}}$ & 18,40 & 20,23 & 16,48 & 18,57 & 17,31 & 17,65 & 16,13 & 15,81 & 16,62 & 15,57 & 14,40 & 13,69 \\
\hline $\mathrm{MnO}$ & 0,26 & 0,25 & 0,27 & 0,29 & 0,26 & 0,29 & 0,22 & 0,21 & 0,32 & 0,34 & 0,35 & 0,32 \\
\hline $\mathrm{MgO}$ & 6,81 & 6,55 & 6,16 & 4,98 & 6,11 & 5,46 & 5,28 & 5,04 & 3,72 & 3,40 & 1,98 & 2,06 \\
\hline $\mathrm{CaO}$ & 6,77 & 11,17 & 6,96 & 8,78 & 10,80 & 8,41 & 8,06 & 8,04 & 7,23 & 6,86 & 5,29 & 5,84 \\
\hline $\mathrm{Na}_{2} \mathrm{O}$ & 3,16 & 2,24 & 2,95 & 3,12 & 2,63 & 3,28 & 2,61 & 2,82 & 4,18 & 3,99 & 4,25 & 5,41 \\
\hline $\mathrm{K}_{2} \mathrm{O}$ & 1,34 & 0,54 & 2,16 & 1,03 & 0,66 & 0,81 & 1,74 & 1,60 & 0,62 & 1,80 & 2,34 & 1,64 \\
\hline $\mathrm{P}_{2} \mathrm{O}_{5}$ & 0,31 & 0,24 & 0,39 & 0,53 & 0,32 & 0,44 & 0,38 & 0,37 & 0,75 & 0,81 & 0,93 & 0,99 \\
\hline Soma & 100,0 & 100,0 & 100,0 & 100,0 & 100,0 & 100,0 & 100,0 & 100,0 & 100,0 & 100,0 & 100,0 & 100,0 \\
\hline P.F. & 3,12 & 1,14 & 1,54 & 1,73 & 1,52 & 1,5 & 1,86 & 2,06 & 2,01 & 1,34 & 0,02 & 1,37 \\
\hline $\mathrm{FeO}^{\mathrm{t}} / \mathrm{MgO}$ & 0,86 & 0,80 & 0,84 & 0,87 & 0,86 & 0,82 & 0,86 & 0,89 & 0,98 & 0,97 & 0,81 & 0,80 \\
\hline Cs & 1,6 & 0,9 & 2,7 & 2,6 & 1,3 & 1,4 & 6,4 & 3,0 & 1,2 & 1,1 & 2,8 & 2,4 \\
\hline $\mathrm{Rb}$ & 40 & 14 & 101 & 31 & 17 & 22 & 162 & 95 & 15 & 49 & 47 & 42 \\
\hline $\mathrm{Ba}$ & 739 & 293 & 2076 & 685 & 416 & 602 & 363 & 360 & 320 & 987 & 1174 & 1160 \\
\hline $\mathrm{Sr}$ & 436 & 276 & 433 & 384 & 307 & 370 & 156 & 166 & 316 & 311 & 343 & 327 \\
\hline $\mathrm{Ga}$ & 24 & 24 & 25 & 25 & 23 & 23 & 23 & 26 & 23 & 24 & 22 & 26 \\
\hline Th & 1,31 & 1,08 & 1,66 & 2,31 & 1,45 & 2,33 & 4,25 & 4,27 & 3,57 & 3,8 & 4,72 & 5,93 \\
\hline $\mathrm{U}$ & 0,37 & 0,31 & 0,45 & 0,63 & 0,41 & 0,55 & 1,12 & 1,13 & 0,92 & 1,0 & 1,26 & 1,54 \\
\hline $\mathrm{Pb}$ & n.d. & n.d. & n.d. & 6 & n.d. & 99 & 8 & 99 & 13 & 6 & 6 & 19 \\
\hline $\mathrm{Nb}$ & 3,1 & 2,4 & 3,9 & 4,9 & 3,1 & 5,3 & 12,9 & 13,5 & 8,8 & 9,7 & 9,4 & 11,6 \\
\hline $\mathrm{Ta}$ & 0,2 & 0,16 & 0,26 & 0,37 & 0,2 & 0,26 & 0,97 & 0,93 & 0,44 & 0,46 & 0,74 & 0,67 \\
\hline $\mathrm{Zr}$ & 86 & 76 & 106 & 152 & 104 & 136 & 240 & 229 & 205 & 207 & 282 & 320 \\
\hline $\mathrm{Hf}$ & 2,6 & 2,6 & 3,2 & 4,5 & 3,1 & 3,5 & 6,3 & 6,5 & 5,4 & 5,4 & 7,7 & 8,2 \\
\hline $\mathrm{Y}$ & 29,7 & 32,2 & 35,1 & 50,5 & 36,8 & 45 & 53,1 & 53,3 & 67,9 & 71,2 & 66,8 & 92,6 \\
\hline $\mathrm{Cr}$ & 90 & n.d. & 110 & n.d. & n.d. & n.d. & 90 & 100 & n.d. & n.d. & n.d. & n.d. \\
\hline $\mathrm{Ni}$ & 220 & 190 & 210 & 170 & 160 & 20 & 180 & 160 & n.d. & n.d. & n.d. & n.d. \\
\hline $\mathrm{V}$ & 448 & 716 & 374 & 471 & 507 & 435 & 358 & 353 & 275 & 225 & 27 & 40 \\
\hline Co & 60 & 60 & 56 & 44 & 48 & 51 & 45 & 50 & 34 & 29 & 13 & 18 \\
\hline As & n.d. & n.d. & n.d. & n.d. & n.d. & n.d. & 9,6 & 5 & n.d. & n.d. & n.d. & n.d. \\
\hline$\overline{\mathrm{Ag}}$ & 0,6 & n.d. & 0,8 & 1,0 & 0,8 & n.d. & 1,4 & 1,8 & n.d. & n.d. & n.d. & n.d. \\
\hline $\overrightarrow{\mathrm{Pt}}$ & 0,3 & n.d. & n.d. & n.d. & n.d. & - & n.d. & 2,3 & - & - & - & - \\
\hline $\mathrm{Pd}$ & 1,1 & n.d. & n.d. & n.d. & n.d. & - & n.d. & 1,4 & - & - & - & - \\
\hline $\mathrm{La}$ & 14,7 & 11,9 & 17,6 & 23,3 & 15,2 & 21,6 & 29,8 & 29,4 & 36,6 & 38,3 & 38,7 & 54,6 \\
\hline $\mathrm{Ce}$ & 33,8 & 28,3 & 40,8 & 53,8 & 35,9 & 49,7 & 65,7 & 64,7 & 83,1 & 86,7 & 89,7 & 123 \\
\hline $\mathrm{Pr}$ & 4,41 & 3,84 & 5,28 & 7,12 & 4,80 & 5,97 & 8,10 & 8,04 & 9,93 & 10,3 & 12,6 & 14,4 \\
\hline $\mathrm{Nd}$ & 20,3 & 18,5 & 24,2 & 32,9 & 22,7 & 26,4 & 35,0 & 35,1 & 42,5 & 44,3 & 52,6 & 59,6 \\
\hline $\mathrm{Sm}$ & 4,92 & 4,95 & 5,89 & 8,34 & 5,89 & 6,97 & 8,28 & 8,09 & 11,0 & 11,5 & 13,1 & 15,3 \\
\hline $\mathrm{Eu}$ & 1,93 & 1,92 & 2,49 & 3,05 & 2,28 & 2,34 & 2,56 & 2,49 & 3,44 & 3,69 & 4,35 & 4,58 \\
\hline $\mathrm{Gd}$ & 5,11 & 5,28 & 6,11 & 8,63 & 6,32 & 7,14 & 8,83 & 8,59 & 11,1 & 11,6 & 13,5 & 15,0 \\
\hline $\mathrm{Tb}$ & 0,89 & 0,96 & 1,05 & 1,53 & 1,14 & 1,24 & 1,59 & 1,53 & 1,90 & 1,97 & 2,14 & 2,58 \\
\hline Dy & 5,41 & 5,89 & 6,3 & 9,31 & 6,91 & 7,65 & 9,61 & 9,35 & 11,8 & 12,1 & 12,7 & 15,9 \\
\hline Ho & 1,06 & 1,15 & 1,25 & 1,82 & 1,35 & 1,56 & 1,89 & 1,8 & 2,43 & 2,51 & 2,61 & 3,26 \\
\hline Er & 3,08 & 3,28 & 3,55 & 5,2 & 3,86 & 4,50 & 5,52 & 5,34 & 6,91 & 7,20 & 7,86 & 9,43 \\
\hline $\mathrm{Tm}$ & 0,45 & 0,48 & 0,52 & 0,76 & 0,57 & 0,64 & 0,83 & 0,78 & 0,97 & 1,01 & 1,15 & 1,37 \\
\hline $\mathrm{Yb}$ & 2,88 & 3,01 & 3,34 & 4,81 & 3,62 & 3,89 & 5,26 & 4,93 & 5,99 & 6,26 & 6,97 & 8,35 \\
\hline $\mathrm{Lu}$ & 0,43 & 0,45 & 0,49 & 0,72 & 0,53 & 0,59 & 0,77 & 0,76 & 0,91 & 0,97 & 1,02 & 1,27 \\
\hline$(\mathrm{La} / \mathrm{Yb})_{\mathrm{N}}$ & 3,09 & 2,40 & 3,19 & 2,94 & 2,54 & 3,37 & 3,43 & 3,61 & 3,70 & 3,71 & 3,37 & 3,96 \\
\hline $\mathrm{La} / \mathrm{Nb}$ & 4,74 & 4,96 & 4,51 & 4,76 & 4,90 & 4,08 & 2,31 & 2,18 & 4,16 & 3,95 & 4,12 & 4,71 \\
\hline $\mathrm{Y} / \mathrm{Nb}$ & 9,58 & 13,42 & 9,00 & 10,31 & 11,87 & 8,49 & 4,12 & 3,95 & 7,72 & 7,34 & 7,11 & 7,98 \\
\hline \multicolumn{13}{|c|}{ Norma CIPW } \\
\hline $\mathrm{Q}$ & 0,00 & 3,07 & 0,00 & 4,85 & 4,18 & 4,11 & 6,41 & 6,25 & 7,74 & 6,68 & 10,06 & 6,92 \\
\hline $\mathrm{Z}$ & 0,02 & 0,01 & 0,02 & 0,03 & 0,02 & 0,02 & 0,04 & 0,04 & 0,04 & 0,04 & 0,05 & 0,06 \\
\hline Or & 6,69 & 2,64 & 11,01 & 5,15 & 3,35 & 4,06 & 8,91 & 8,21 & 3,14 & 9,23 & 12,08 & 8,56 \\
\hline $\mathrm{Ab}$ & 22,55 & 15,76 & 21,4 & 22,29 & 18,99 & 23,6 & 19,05 & 20,57 & 30,35 & 29,18 & 31,46 & 40,25 \\
\hline $\mathrm{An}$ & 20,51 & 16,52 & 20,63 & 13,79 & 16,57 & 16,32 & 17,24 & 17,72 & 11,83 & 10,26 & 9,35 & 5,44 \\
\hline $\mathrm{Di}$ & 0,68 & 16,64 & 1,64 & 10,0 & 16,36 & 7,91 & 6,9 & 6,52 & 5,52 & 6,32 & 2,63 & 7,3 \\
\hline $\mathrm{Hy}$ & 12,43 & 5,87 & 11,6 & 5,83 & 5,4 & 7,9 & 8,13 & 7,81 & 5,38 & 4,41 & 3,1 & 1,14 \\
\hline $\mathrm{Ol}$ & 1,11 & 0,0 & 0,57 & 0,0 & 0,0 & 0,0 & 0,0 & 0,0 & 0,0 & 0,0 & 0,0 & 0,0 \\
\hline $\mathrm{Hm}$ & 31,09 & 33,65 & 28,3 & 31,32 & 29,51 & 30 & 27,77 & 27,3 & 28,51 & 26,95 & 25,17 & 24,09 \\
\hline Il & 0,53 & 0,49 & 0,56 & 0,57 & 0,51 & 0,54 & 0,46 & 0,44 & 0,59 & 0,64 & 0,66 & 0,6 \\
\hline $\mathrm{Tn}$ & 3,93 & 4,97 & 3,79 & 5,29 & 4,6 & 4,78 & 4,45 & 4,5 & 5,51 & 4,82 & 3,71 & 3,79 \\
\hline $\mathrm{Ap}$ & 0,63 & 0,48 & 0,81 & 1,06 & 0,64 & 0,9 & 0,78 & 0,76 & 1,53 & 1,66 & 1,95 & 2,08 \\
\hline Total & 100,17 & 100,1 & 100,33 & 100,18 & 100,13 & 100,14 & 100,14 & 100,12 & 100,14 & 100,19 & 100,22 & 100,23 \\
\hline
\end{tabular}

Observações: elementos maiores recalculados para base anidra e expressos em \% em peso, elementos traço expressos em ppm, exceto Pt e Pd, expressos em ppb.

Abreviações: Db - diabásio; Gb - gabro; Dr - diorito; P.F. - perda ao fogo; n.d. não detectado. 

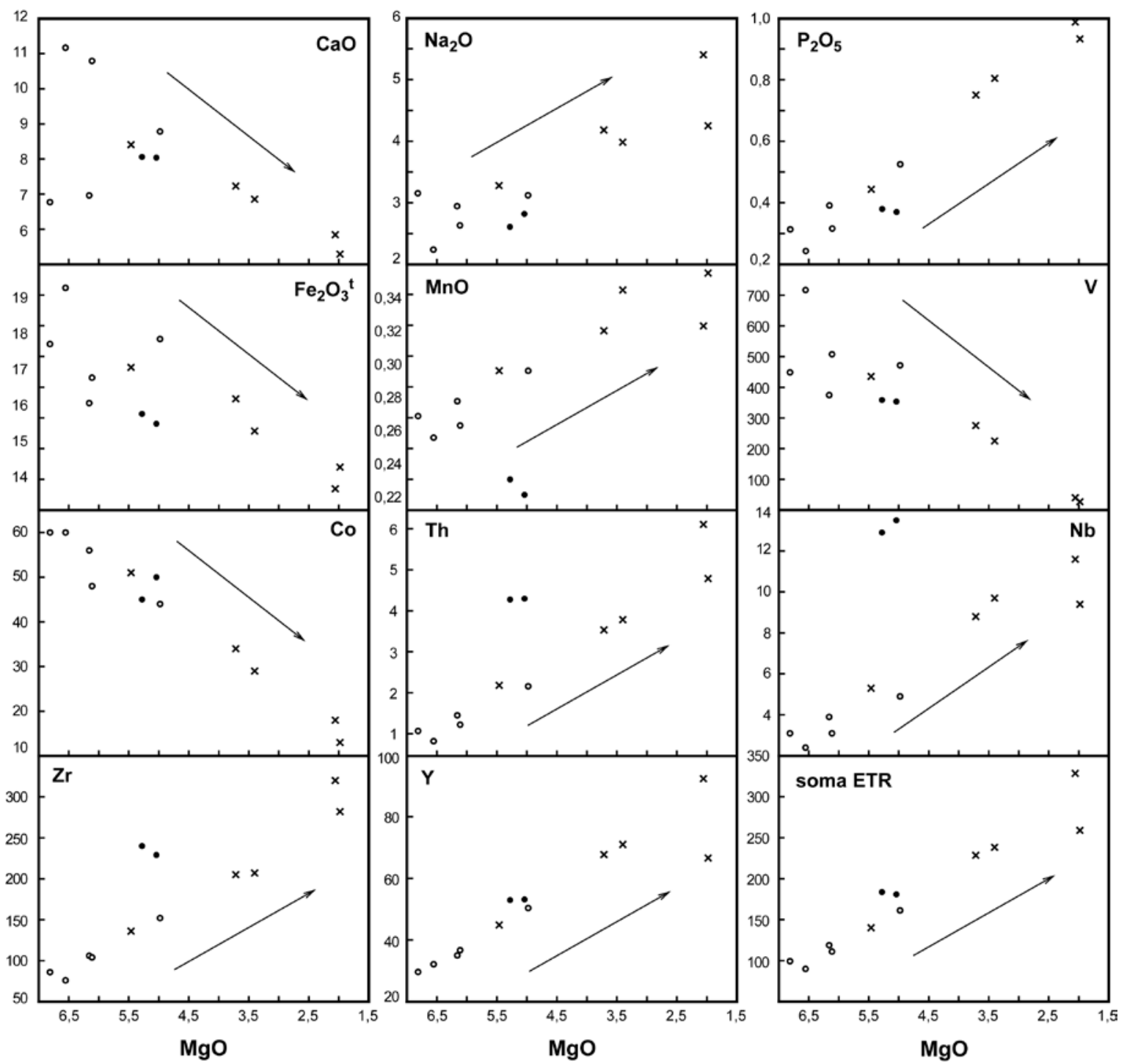

Figura 14 - Diagramas binários das rochas básicas a intermediárias da Formação Quarenta Ilhas. Símbolos: • - diabásios alto-Nb; o - diabásios baixo-Nb; $x$ - gabros e dioritos. As setas indicam sentido da diferenciação.
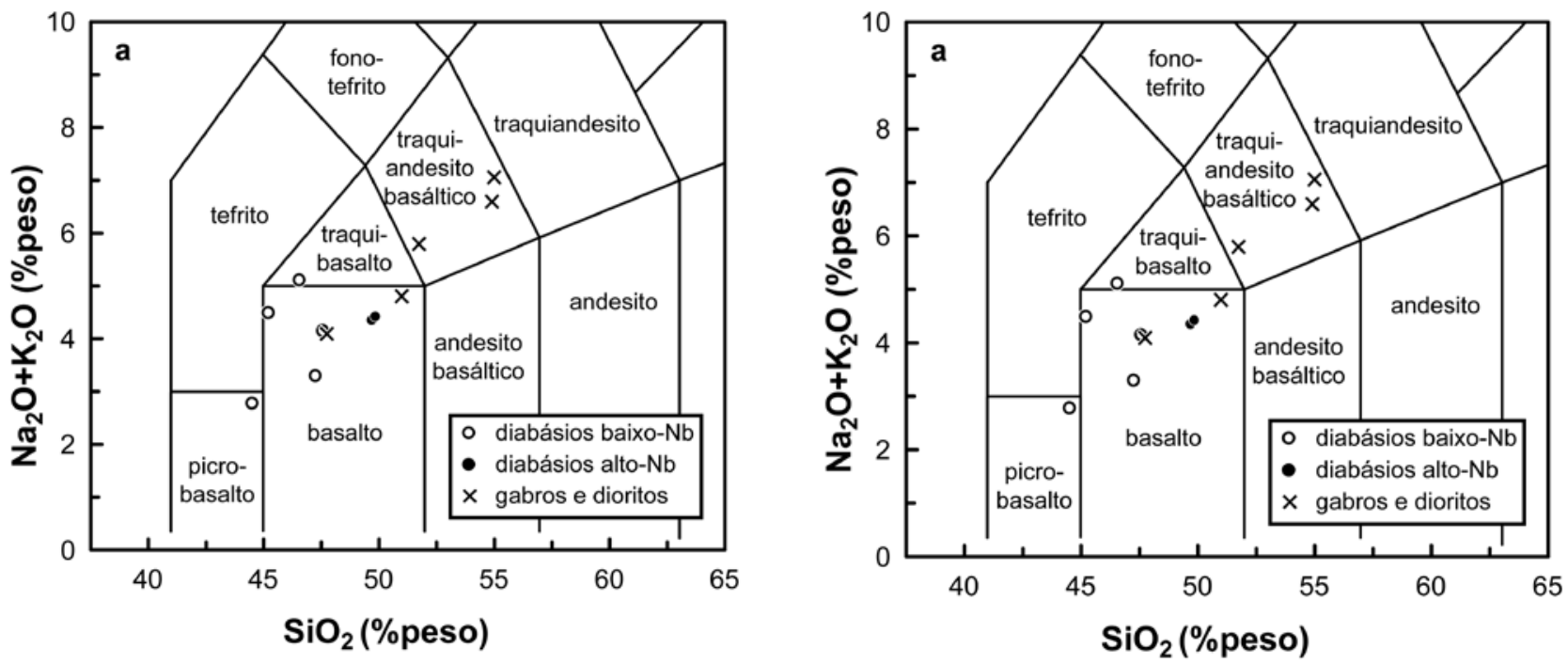

Figura 15 - Diagramas de classificação química das rochas básicas a intermediárias. a) parte do diagrama TAS de Middlemost (1994), b) Diagrama $\mathrm{Zr} / \mathrm{TiO}_{2} v \mathrm{sNb} / \mathrm{Y}$ de Winchester \& Floyd (1977). 

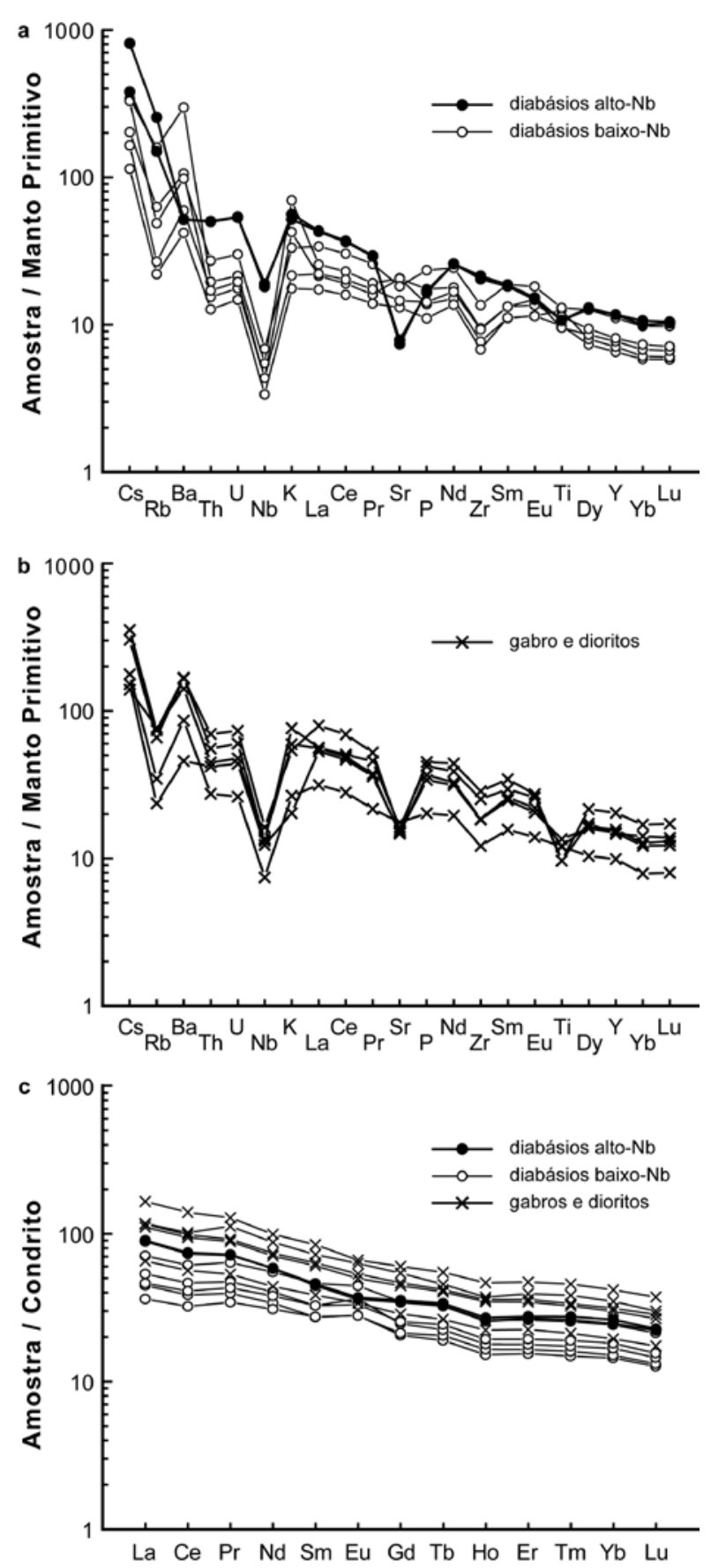

Figura 16 - Diagramas multi-elementos (a, b) e de ETR (c) das rochas básicas e intermediárias. a,b) padrão de manto primitivo de Sun \& McDonough (1989); c) padrão condrítico de Boynton (1984).

\& Tarney (1979) consideram essa variação como o resultado do enriquecimento do manto litosférico por fluidos derivados da subducção. Elementos alcalinos e alcalinos terrosos seriam liberados na fase aquosa gerada pela desidratação de minerais secundários, enquanto elementos de alto potencial iônico permaneceriam nas fases residuais da litosfera subductada. A distribuição dos ETR normalizados (Fig. 16c) indica conteúdos superiores a 10 vezes o padrão condrítico,

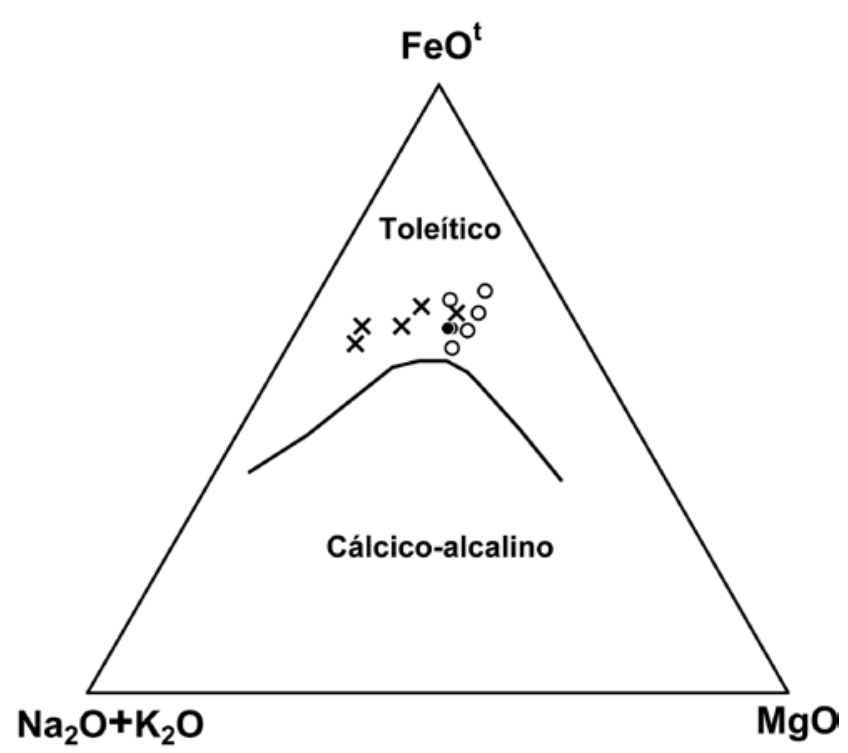

Figura 17 - Diagrama AFM de Irvine \& Baragar (1971) para as rochas básicas a intermediárias. Símbolos: idem a figura 13.

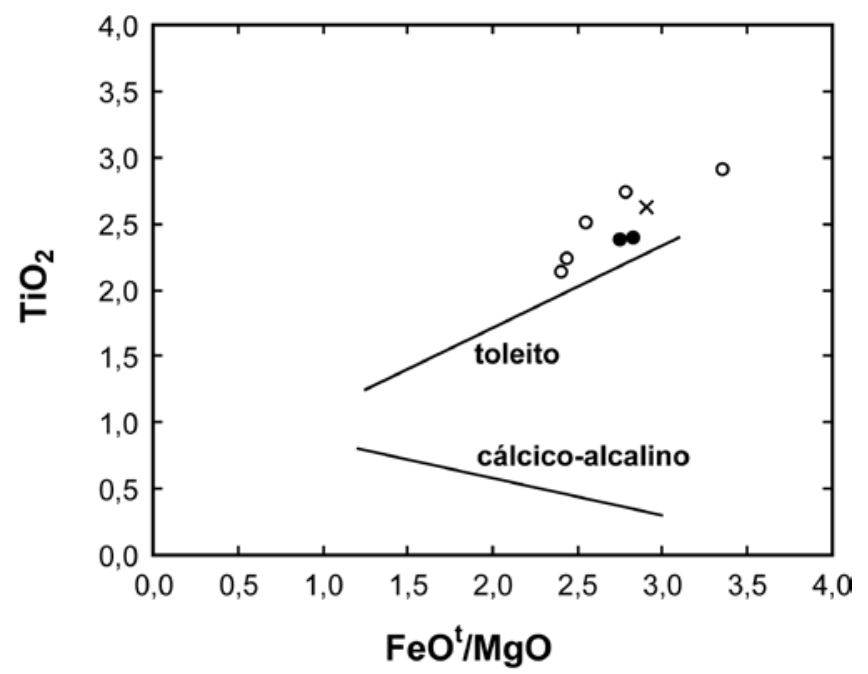

Figura 18 - Diagrama $\mathrm{TiO}_{2} \mathrm{vsFeO}^{t} / \mathrm{MgO}$ de Miyashiro (1974) para as rochas básicas. Símbolos: idem a figura 13.

com crescimento de ETRL em relação à ETRP $(\mathrm{La} / \mathrm{Yb}$ entre 3,9 e 6,5). Esse padrão sugere que os magmas básicos podem ter sido extraídos de uma fonte do tipo granada lherozlito.

CONCLUSÕES O posicionamento Formação Quarenta Ilhas ocorreu em um ambiente intracratônico, sendo precedido pelas atividades orogenéticas relacionadas ao Ciclo Transamazônico $(\sim 2,0 \mathrm{Ga})$, pelo magmatismo pós-collisional Uatumã $(\sim 1,88 \mathrm{Ga})$ e pelo magmatismo anorogênico da Suíte Madeira $(\sim 1,83 \mathrm{Ga})$, num ambiente francamente intracratônico. As rochas básicas possuem 


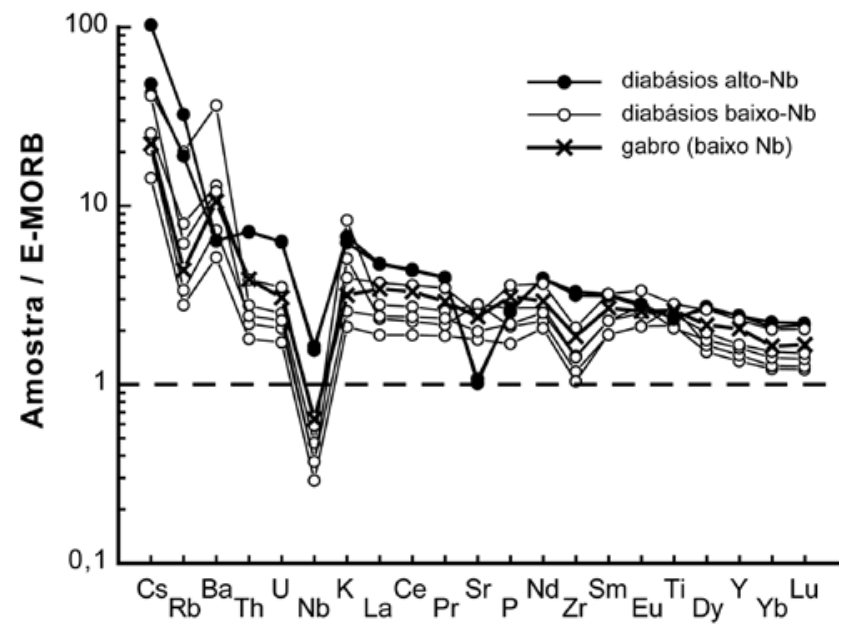

Figura 19 - Diagrama multi-elementos das rochas básicas da Formação Quarenta Ilhas, normalizados segundo o padrão E-MORB de Sun \& McDonough (1989).

afinidade toleítica e evoluem até termos intermediários por cristalização fracionada. As ocorrências estudadas consistem de intrusões rasas constituídas por rochas de textura fina (diabásios) a grossa (gabros e dioritos). O plagioclásio precoce possui composição labradorítica nas rochas básicas e de andesina nas intermediárias, ambos evoluindo até oligoclásio. A olivina está substituída pseudomorficamente por ferro-saponita. Os piroxênios possuem composição dominantemente augítica, seguindo um enriquecimento $\mathrm{em} \mathrm{Fe}$ em direção aos termos mais diferenciados, o que favorece a hipótese de cristalização fracionada como mecanismo principal na evolução das rochas básicas. Diopsídio ocorre nos termos mais primitivos. O anfibólio ocorre nos termos dioríticos e origina-se do aumento da atividade de $\mathrm{H}_{2} \mathrm{O}$ no magma. Consiste de ferro-hornblenda parcialmente reequilibrada para ferro-actinolita. Os óxidos de Fe-Ti são definidos como ilmenita e magnetita reequilibrada por processos subsolvus, gerando feições de exsolução/ oxidação, que podem estar indicando aumento da $f \mathrm{O}_{2}$.

As rochas básicas são toleitos saturados a su- persaturados em $\mathrm{SiO}_{2}$, alto $\mathrm{TiO}_{2}(>2,0 \%)$ e médio-K, exibindo trend evolutivo para as composições dioríticas compatíveis com processos de cristalização fracionada. Os padrões de elementos traço e ETR sugerem a participação de uma fonte de manto litosférico enriquecido, do tipo granada lherzolito, previamente modificada por subducção. Duas amostras de diabásio possuem maiores conteúdos de $\mathrm{Nb}, \mathrm{Ta}, \mathrm{Zr}, \mathrm{Th}, \mathrm{U}$ e mais baixo conteúdo de Sr. Essas amostras ocorrem intrudindo vulcanitos do Grupo Iricoumé, num contexto geológico relativamente distinto das amostras com baixo-Nb, as quais intrudem as rochas sedimentares da Formação Urupi. Estas características pode indicar mais de um evento na evolução da Formação Quarenta Ilhas, ou um evento temporalmente distinto, relacionado à Suíte Madeira $(1,83 \mathrm{Ga})$, ou mesmo a manifestações mais jovem relacionadas à Formação Seringa $(1,2 \mathrm{Ga})$. Destaca-se ainda conteúdos de $\mathrm{Pt}, \mathrm{Pd}, \mathrm{Cu}, \mathrm{Pb}, \mathrm{As}$ e $\mathrm{Ag}$ acima do limite de detecção nas amostras alto- $\mathrm{Nb}$ (Tab. 6), apontando para um cenário prospectivo mais favorável daquele observado para as ocorrências típicas da Formação Quarenta Ilhas. Neste contexto, a aquisição de dados geocronológicos e isotópicos pode vir a contribuir para um melhor entendimento das ocorrências de rochas básicas no Distrito Mineiro de Pitinga.

Agradecimentos Os autores agradecem a UFRGS e a LMU e seus funcionários pela contribuição e suporte ao desenvolvimento da tese. Ao CNPq pelo suporte financeiro através do Projeto CT-MINERAL (505625/2004-0), pela bolsa de doutorado do primeiro autor e pelas bolsas de produtividade de E. F. Lima, L. V. S. Nardi e A. C. Bastos Neto. Ao CTMINERAL/ ADIMB/DNPM/FINEP "Caracterização de depósitos minerais em distritos mineiros da Amazônia" que apoiou as atividades de campo. A CAPES-PDEE e a Pró-reitoria de Pós-graduação pela concessão da bolsa de estágio sanduíche na LMU (1432/07-9). À Dra. Saskia Bernstein (LMU) pelo auxílio nos procedimentos analíticos de microssonda. À Mineração Taboca S.A. - Grupo Paranapanema, pelas informações disponibilizadas e pelo suporte nas campanhas de campo. Aos revisores ad hoc pelas críticas e sugestões.

\section{Referências}

Araújo J.F.V., Montalvão R.M.G., Lima M.I.C., Fernandes P.E.C.A., Cunha F.M.B., Fernandes C.A.C., Basei M.A.S. 1976. Geologia da Folha SA.21 - Santarém. Brasil. DNPM. Projeto RADAMBRASIL. Levantamento de Recursos Naturais, 10:17-130.

Bellieni G., Comin-Chiaramonti P., Marques L.S., Melfi A.J., Nardy A.J.R., Papatrechas C., Piccirillo E.M., Roisenberg A., Stolfa D. 1986. Petrogenetic aspects of acid and basaltic lavas from the Paraná Plateau (Brazil): geological, mineralogical and petrochemical relationships. $J$. Petrol., 27:915-944.

Best, M.G. 1975. Amphibole-bearing cumulate inclusions, Grand Canyon, Arizona, and their bearing on silica un- dersaturated hydrous magmas in the upper mantle. $J$. Petrol., 16:212-236.

Bizzinella G.A., Andrade A.F., Yamaguti H.S., Oliveira J.R., Carmona J.R.M., D’Antona R.J.G., Lopes R.C., Melo A.F.F. 1980. Projeto Tapajós-Sucunduri. Relatório Final. Manaus, CPRM-DNPM, v.6.

Boynton W.V. 1984. Cosmochemistry of the rare earth elements: meteorite studies. In: Henderson, P. (ed.) Rare Earth Element Geochemistry. Amsterdam, Elsevier, p. 63-114.

Buddington A.F. \& Lindsley D.H. 1964. Iron-titanium oxide minerals and synthetic equivalents. J. Petrol., 5(2):310357. 
Carmichael I.S.E. 1967. The iron-titanium oxides of salic volcanic rocks and their associated ferromagnesian silicates. Contr. Min. Petrol., 14(1):36-64.

Carmichael I.S.E. \& Nicholls J. 1967. Iron-titanium oxides and oxygen fugacities in volcanic rocks. J. Geophys. Res., 72:4665-4687.

Costi H.T., Dall'Agnol R., Moura C.A.V. 2000. Geology and $\mathrm{Pb}-\mathrm{Pb}$ Geochronology of Paleoproterozoic Volcanic and Granitic Rocks of Pitinga Province, Amazonian Craton, Northern Brazil. Intern. Geol. Rev., 42:832-849.

Dall'Agnol R., Rämö O.T., Magalhães M.S., Macambira M.J.B. 1999. Rapakivi granites from Brazil and adjacent areas. Precambr. Res., 95:9-39.

Deer W.A., Howie R.A., Zussman J. 1992. An introduction to the rock-forming minerals. 2.ed., Longman, $696 \mathrm{p}$.

Ferron J.M.T.M., Bastos Neto A.C., Lima E.F., Costi H.T., Moura C.A.V., Prado M., Pierosan R., Galarza M.A. 2006. Geologia e geocronologia $\mathrm{Pb}-\mathrm{Pb}$ de rochas graníticas e vulcânicas ácidas a intermediárias Paleoproterozóicas da Província Pitinga, Craton Amazônico. Rev. Bras. Geoc., 36(3):499-512.

Ferron J.M.T.M., Bastos Neto, A.C., Lima E.F., Nardi L.V.S., Costi H., Pierosan R., Prado M. 2010. Petrology, Geochemistry, and Geochronology of Paleoproterozoic Volcanic and Granitic Rocks (1.89 to $1.88 \mathrm{Ga}$ ) of the Pitinga Province, Amazonian Craton, Brazil. Journal of South American Earth Sciences, 29:483-497.

Fitton J.G., James D., Kempton P.D., Ormerod D.S., Leeman W.P. 1988. The role of lithospheric mantle in the generation of late Cenozoic basic magmas in the western United States. In: Cox K.G. \& Menzies M.A. (eds.) Oceanic and continental lithosphere: similarities and differences. J. Petrol. Spec. Vol., p.109-138.

Frost B.R. \& Lindsley D.H. 1992. Equilibria among Fe-Ti oxides, pyroxene, olivine and quartz: Part II. Application. Am. Min., 77:1004-1020.

Hebeda E.H., Boelrijk N.A.I.M., Priem H.N.A., Verdurmen E.A.T.H., Vershure R.A. 1973. Excess radiogenic argon in the Precambrian Avanavero Dolerite in western Surinam (South America). Earth Plan. Sci. Let., 20(2):189200.

Horbe M.A., Horbe A.C., Costi H.T., Teixeira J.T. 1991. Geochemical charateristics of cryolite-tin-bearing granites from the Pitinga Mine, northwestern Brazil: a review. J. Geoch. Expl., 40:227-249.

Irvine T.N. \& Baragar W.R.A. 1971. A guide to chemical classification of the common volcanic rocks. Can. J. Earth Sci., 8:523-548.

Issler R.S., Andrade A.R.F., Montalvão R.M.G., Guimarães G., Silva G.G., Lima M.I.C. 1974. Geologia da Folha SA.22 - Belém. Brasil. DNPM. Projeto RADAMBRASIL. Levantamento de Recursos Naturais, 5:7-182.

Klein E.L., Almeida M.L.V., Bahia R.B.C., Espírito Santo M.L., Ferreira A.L. (orgs.) 2001. Geologia e Recursos Minerais da Província Mineral do Tapajós: Folhas: Vila Mamãe Anã (SB.21-V-D), Jacareacanga (SB.21-Y-B), Caracol (SB.21-X-C), Vila Riozinho (SB.21-Z-A) e Rio Novo (SB.21-Z-C). Escala 1:500.000. Brasília, CPRM/ DIEDIG/DEPAT, CD-Rom.

Leake B.E., Woolley A.R., Arps C.E.S., Birch W.D., Gilbert
M.C., Grice J.D., Hawthorne F.C., Kato A., Kisch H.J., Krivovichev V.G., Linthout K., Laird J., Mandarino J., Marsech W.V., Nickel E.H., Rock N.M.S., Schumacher J.C., Smith D.C., Stephenson N.C.N., Ungaretti L., Whittaker E.J.W., Youzhi G. 1997. Nomenclature of Amphiboles: report of the Subcommittee on Amphiboles of the International Mineralogical Association Commission on New Minerals and Mineral Names. Min. Mag., 61:295-321.

Leat P.T., Thompson R.N., Morrinson M.A., Hemdry G.L., Dickin A.P. 1988. Compositionally diverse MioceneRecent rift-related magmatism in northwest Colorado: partial melting and mixing of mafic magmas from 3 different asthenospheric and lithospheric mantle sources. In: Cox K.G. \& Menzies M.A. (eds.) Oceanic and continental lithosphere: similarities and differences. J. Petrol. Spec. Vol., p.109-138.

Lenharo S.L. 1998. Evolução magmática e modelo metalogenético dos granitos mineralizados da região de Pitinga, Amazonas, Brasil. Tese de Doutoramento, Escola Politécnica, Universidade de São Paulo, 290 p.

Lenharo S.L., Pollard P.J., Born H. 2003. Petrology and textural evolution of granites associated with tin and raremetals mineralization at the Pitinga mine, Amazonas, Brazil. Lithos, 66:37-61.

Mandetta P., Veiga Jr. J.P., Oliveira J.R. 1974. Reconhecimento geológico ao longo do rio Pitinga, afluente do rio Uatumã. Manaus, CPRM, p. 31.

Middlemost E.A.K. 1994. Naming materials in magma/igneous rock system. Earth Sci. Rev., 37:215-224.

Miyashiro A. 1974. Volcanic rock series in island arcs and active continental margins. Am. J. Sci., 274:321-355.

Montalvão R.M.G. 1975. Grupo Uatumã no Craton Guianês, In: DNPM, Conferência Geológica Interguianas, 10, Belém, Anais, p. 286-339.

Morimoto C.N. 1988. Nomenclature of pyroxenes. Am. Min., 73:1123-1133.

Nomade S., Poulclet A., Chen Y. 2002. The French Guyana doleritic dykes: geochemical evidences of three populations and new data for the Jurassic Central Atlantic Magmatic Province. J. Geodyn., 34:595-614.

Norcross C., Davis D.W., Spooner E.T.C., Rust A. 2000. $\mathrm{U}-\mathrm{Pb}$ and $\mathrm{Pb}-\mathrm{Pb}$ age constraints on Paleoproterozoic magmatism, deformation and gold mineralization in the Omai area, Guyana Shield. Precam. Res., 102:69-86.

Oliveira M.J.R., Luzardo R., Faria M.S.G., Pinheiro S.S. 1996. A Suíte Intrusiva Água Branca no sudeste do Estado de Roraima. In: SBG-Núcleo Norte, Simp. Geol. Amaz., 5, Belém, Boletim de Resumos Expandidos e Guia de Excursões, 2:86-89.

Pearce J.A. \& Cann J.R. 1973. Tectonic settings of basic volcanic rocks determined using trace element analyses. Earth Plan. Sci. Let., 19:290-300.

Pessoa M.R., Santiago A.F., Andrade A.F., Barreto E.L., Nascimento J.O., Santos J.O.S., Oliveira J.R., Lopes R.C., Prazeres W.V. 1977. Projeto Jamanxim. Relatório Final. CPRM/DNPM, 3v, 614p.

Pierosan R., Lima E.F., Nardi L.V.S., de Campos C.P., Bastos Neto A.C., Ferron J.M.T.M., Prado M. (no prelo). Paleoproterozoic $(\sim 1.88 \mathrm{Ga})$ felsic volcanism of the Iricoumé 
Group in the Pitinga Mining District area, Amazonian Craton, Brazil: insights in ancient volcanic processes from field and petrologic data. Anais da Acad. Bras. Cien. (aceito, sem data de publicação).

Roberts M.P., Pin C., Clemens D., Paquette J.L. 2000. Petrogenesis of Mafic to Felsic Plutonic Rock Associations: the Calc-alkaline Quérigut Complex, French Pyrenees. J. Petrol., 41(6):809-844.

Robinson P., Spear F.S., Schumacher J.C., Laird J., Klein C., Evans B.W., Doolan B.L. 1981. Phase relations of metamorphic amphiboles: natural occurrence and theory. Rev. in Min., 9B:1-228.

Santos J.O.S. \& Loguércio S.O.C. 1984. A parte meridional do Cráton Amazônico (Escudo Brasil Central) e as Bacias do Alto Tapajós e Parecis-Alto Xingu. In: Schobbenhaus C., Campos D.A., Derze G.R., Asmus H.E. (coords.) 1984. Geologia do Brasil. Texto explicativo do Mapa Geológico do Brasil e da Área Oceânica adjacente incluindo Depósitos Minerais, Escala 1:2.500.000. Brasília, DNPM. 501 p.

Santos J.O.S., Hartmann L.A., Gaudette H.E., Groves D.I., McNaughton N.J., Fletcher L.R.A. 2000. New understanting of the Provinces of Amazon Craton based on Integration of Field Mapping and $\mathrm{U}-\mathrm{Pb}$ and $\mathrm{Sm}-\mathrm{Nd}$ geochronology. Gond. Res., 3(4):453-488.

Santos J.O.S., Hartmann L.A., McNaughton N.J., Fletcher I.R. 2002. Timming of mafic magmatism in the Tapajós Province (Brazil) and implications for the evolution of the Amazon Craton: evidence from baddeleyite and zircon U-Pb SHRIMP geochronology. J. South Am. Earth Sci., 15:409-429.

Saunders A.D. \& Tarney J. 1979. The geochemistry of basalts from a back-arc spreading centre in the East Scotia Sea. Geochim. Cosmo. Acta, 43:555-572.
Shervais J.W. 1982. Ti-V plots and the petrogenesis of modern and ophiolitic lavas. Earth Plan. Sci. Let., 59:101-118.

Sun S.S. \& McDonough W.E. 1989. Chemical and isotopic systematic of oceanic basalt: implications for mantle composition and processes. In: Saunders A.D. \& Norry M.J. (eds.) Magmatism in the Ocean Basins. Geol. Soc. Spec. Publ., 42:313-345.

Tassinari C.C.G. \& Macambira M.J. 1999. Geochronological Provinces of the Amazonian Craton. Episodes, 22(3):174-182.

Thompson R.N. \& Morrison M.A. 1988. Asthenospheric and lower-lithospheric mantle contributions to continental extension magmatism: an example from British Tertiary Province. Chem. Geol., 68:1-15.

Valério C.S., Souza V.S., Macambira M.J.B., Galarza M.A. 2006. Geoquímica e geocronologia $\mathrm{Pb}-\mathrm{Pb}$ em zircao da Suíte Intrusiva Água Branca, município de Presidente Figueiredo (AM): evidências de colisao no Paleoproterozóico da Amazônia Ocidental. Rev. Bras. Geoc., 36(2):359-370.

Veiga Jr., J.P., Nunes A.C.B., Fernandes A.S., Amaral J.E., Pessoa M.R., Cruz S.A.S. 1979. Projeto Sulfetos de Uatumã. Relatório Final. Manaus, DNPM/CPRM, 7v.

Winchester J.A. \& Floyd P.A. 1977. Geochemical discrimination of different magma series and their differentiation products using immobile elements. Chem. Geol., 20:325-343.

Yoder H.S. \& Tilley C.E. 1962. Origin of basalt magmas: an experimental study of natural and synthetic rock systems. J. Petrol., 3:342-532.

Manuscrito ID 15765

Submetido em 19 de outubro de 2009 Aceito em 10 setembro de 2010 